\title{
Model-based Analysis of High Shear Wet Granulation from Batch to Continuous Processes in Pharmaceutical Production- A Critical Review th
}

\author{
Ashish Kumar ${ }^{\mathrm{a}, \mathrm{b}}$, Krist V. Gernaey ${ }^{\mathrm{c}}$, Thomas De Beer ${ }^{\mathrm{b}, 1}$, Ingmar Nopens ${ }^{\mathrm{a}, *}$ \\ ${ }^{a}$ BIOMATH, Dept. of Mathematical Modelling, Statistics and Bioinformatics, Faculty of Bioscience Engineering, Ghent \\ University, Coupure Links 653, B- 9000 Gent, Belgium \\ ${ }^{b}$ Laboratory of Pharmaceutical Process Analytical Technology, Dept. of Pharmaceutical Analysis, Faculty of Pharmaceutical \\ Sciences, Ghent University, Harelbekestraat 72, B-9000 Ghent, Belgium \\ ${ }^{c}$ Center for Process Engineering and Technology, Department of Chemical and Biochemical Engineering, Technical \\ University of Denmark, DK-2800 Kongens Lyngby, Denmark
}

\begin{abstract}
The manufacturing of pharmaceutical dosage forms, which has traditionally been a batch-wise process, is now also transformed into a series of continuous operations. Some operations such as tabletting and milling are already performed in continuous mode, while the adaptation towards a complete continuous production line is still hampered by complex steps such as granulation and drying which are considered to be too inflexible to handle potential product change-overs. Granulation is necessary in order to achieve good flowability properties and better control of drug content uniformity. This paper reviews modelling and supporting measurement tools for the high shear wet granulation (HSWG) process, which is an important granulation technique due to the inherent benefits and the suitability of this unit operation for the desired switch to continuous mode. For gaining improved insight of the complete system, particle-level mechanisms are required to be better understood, and linked with an appropriate meso- or macro-scale model. A brief review has been provided to understand the mechanisms of the granulation process at micro or particle-level such as those involving wetting and nucleation, aggregation, breakage and consolidation. Further, population balance modelling (PBM) and the discrete element method (DEM), which are the current state-of-the-art methods for granulation modelling at micro- to meso-scale, are discussed. The DEM approach has a major role to play in future research as it bridges the gap between micro- and meso-scales. Furthermore, interesting developments in the measurement technologies are discussed with a focus towards inline measurements of the granulation process to obtain experimental data which are required for developing good models. Based on the current state of the developments, the review focuses on the twin screw granulator as a device for
\end{abstract}

\footnotetext{
*Email address: ingmar.nopens@ugent.be, Tel.: +32 (0)9 26461 96; fax: +32 (0)9 2646220

Email addresses: ashishku.ashishkumar@ugent.be (Ashish Kumar), kvg@kt.dtu.dk (Krist V. Gernaey), thomas.debeer@ugent.be (Thomas De Beer)

URL: www.biomath.ugent.be (Ashish Kumar)

${ }^{1}$ Shared last authorship
} 
continuous HSWG and attempts to critically evaluate the current process. As a result, a set of open research questions are identified. These questions need to be answered in the future in order to fill the knowledge gap that currently exists both at micro- and macro-scale, and which is currently limiting the further development of the process to its full potential in pharmaceutical applications.

Keywords: high shear wet granulation, process modelling, calibration, measurement techniques, twin-screw granulator

\section{Introduction}

Granulation is a size enlargement process to form granules with controlled properties, starting from a particulate feed and a liquid as raw materials. It is a key process adopted in a range of industries for production of pharmaceuticals, detergents, agricultural and food products, agro-chemicals, enzymes etc. 5 Granulation is mainly performed to improve the flowability of powders, to reduce dustiness and co-mixing of materials which will otherwise segregate or form a cake $[1,2]$. The major granule properties such as granule size distribution (GSD) and porosity, are driven by the rate of various macroscopic mechanisms during the granulation process, e.g. nucleation, aggregation, layering, breakage, consolidation [1-3].

Despite the challenges involved, continuous processing has become preferable for all major industries in the past decades due to the fact that continuous operation usually comes with several benefits for the process (Table 1). However, the pharmaceutical industry is a clear exception, and has for many years mainly relied on conventional batch manufacturing, largely due to a rigid regulatory framework and due to uncertainty in industry about the attitude of the regulators towards more continuous production processes. laboratories, which is in sharp contrast to the real-time in-process analysis methods which are needed for continuous processing. Continuous real-time quality monitoring and control is indeed indispensable for efficient continuous production.

The introduction of the process analytical technology (PAT) guidance [4] was an important milestone for the pharmaceutical industry, since it is one of the first documents published by regulatory authorities promoting a new pharmaceutical production model based on the Quality by Design (QbD) concept. The QbD concept relies on a science- and risk- based holistic development of processes and products such that, quality cannot be tested into products; it should be built-in or should be by design. In addition to the new concepts considered by the United States Food and Drug Administration (US FDA), the use of quality risk management principles and the application of an appropriate pharmaceutical quality system, as defined within the International Conference on Harmonization ( $\mathrm{ICH})$ documents Q8, Q9 and Q10 [5-7] provided the platform for establishing a new release decision-making strategy for marketed products, i.e. the Real 


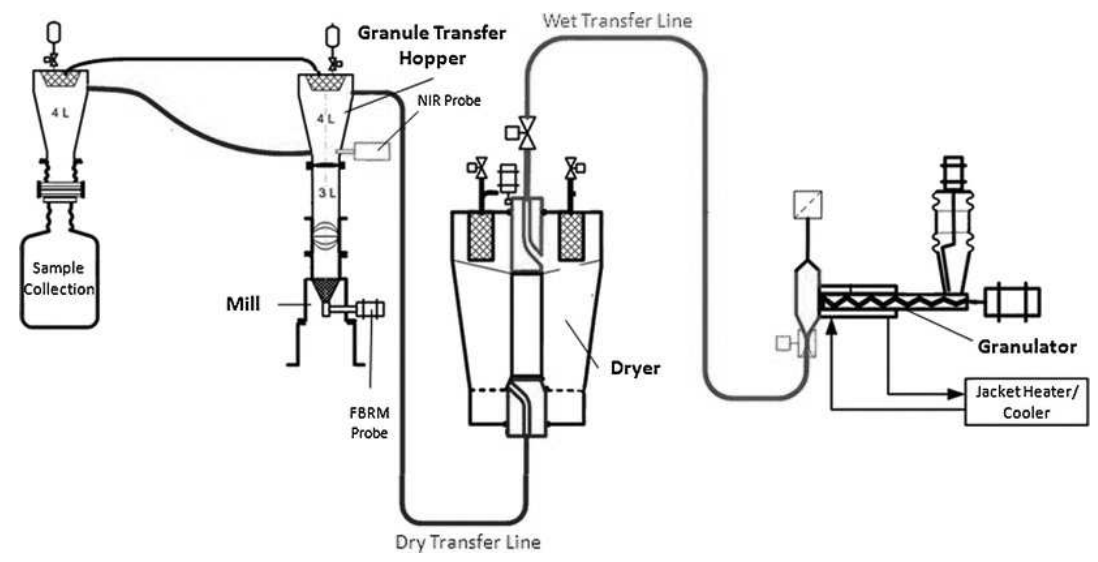

Figure 1: Schematic diagram of industrial granulation systems operated in a continuous production line [10].

Time Release Testing (RTRT) strategy [8]. Furthermore, ICH published a more recent and extensive guidance for harmonising the scientific and technical principles related to the description and justification of the drug development and complete manufacturing process [9]. All these developments and publications have reduced the regulatory uncertainty, and opened new and exciting possibilities for innovation in pharmaceutical manufacturing, resulting in significant efforts for designing new and more efficient production strategies. Continuous manufacturing of solid dosage pharmaceutical products is in line with the efforts aiming at improving product quality, reducing manufacturing cost, and essentially providing safer products to the patients. The one-in-one-out principle for the raw materials in this production scheme leads to reduced cycle times and improved process throughput. Schaber et al. [11] showed that continuous processing has a clear economic advantage over batch processing. Cervera-Padrell et al. [12] demonstrated that the switch from batch to continuous processing for organic synthesis of small molecules resulted in a reduction of the process mass intensity by about $50 \%$, thus resulting in a considerably greener continuous production process. The desired paradigm shift from batch to continuous mode at production scale in the pharmaceutical sector requires a reliable continuous granulation process. An example of a production line used for the continuous manufacturing of tablets is shown in Figure 1 [10]. Some of the process steps in the pharmaceutical production process are in fact continuous as such (e.g. milling, tabletting), but the production of granules is typically performed using inherent batch unit operations. Various granulation techniques which are widely used in the pharmaceutical industry are summarised in Table 2.

Wet granulation is a commonly used unit operation for solid dosage form manufacturing which is attributed to the more uniform distribution of formulation ingredients that is obtained. Various wet granulation techniques including fluidised-bed aggregation and extrusion have been developed and used (Figure 2). However, compared to other granulation methods, the high-shear wet granulation (HSWG) methods offer several advantages as listed in Table 3. As the wetting, agglomeration, consolidation and discharge are quickly 

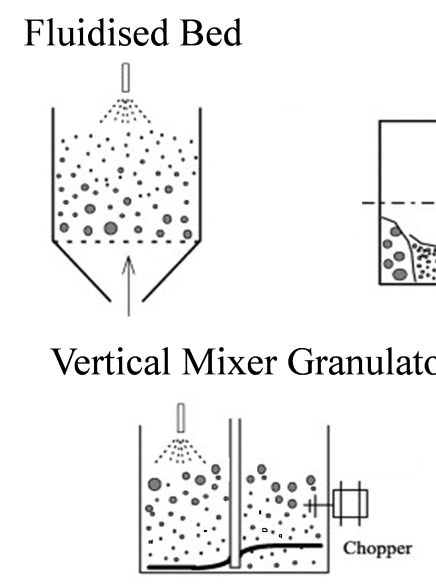

Rotating Drum

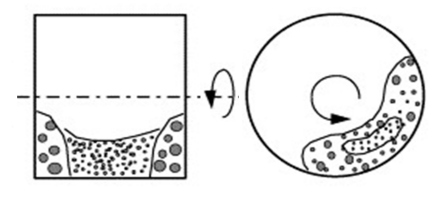

\section{Rotating Pan}
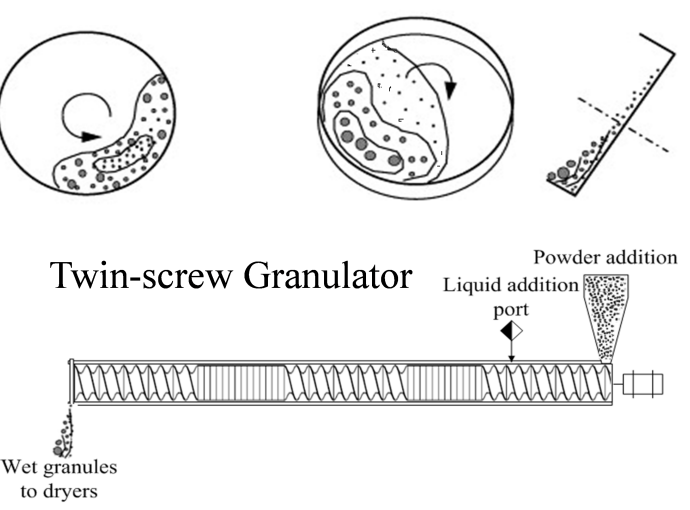

Figure 2: Overview of types of equipment used in wet granulation

performed in the same equipment HSWG is also promising with respect to switching towards continuous processing. Despite these advantages, there are some challenges compared with low-shear granulation processes: e.g. HSWG can produce less compressible granules due to over-wetting and a narrow range of operating conditions, which demands for strong control over the process. Vervaet and Remon [13] reviewed the continuous granulation techniques extensively, and due to other inherent benefits in terms of ease in continuous operation, operations-integration and scale-up possibility, the high-shear twin-screw granulation system has received most attention in the last decades. To date these systems are even commercially available as continuous twin-screw granulators (TSG), e.g. the ConsiGma ${ }^{\mathrm{TM}}$ systems by GEA Pharma Systems nv., Wommelgem, Belgium [14] and Pharma 16 TSG by Thermo Fisher Scientific, Karlsruhe, Germany [15].

Nevertheless, there is a clear need to acquire more fundamental understanding of the continuous granulation processes. Improved process understanding can then result in improvements in equipment design, process control and processing efficiency. Application of computational process modelling tools is becoming more common and now playing a crucial role in efforts to gain knowledge about these processes. Some recent reviews have underlined their diverse application in the pharmaceutical industry [16, 17] , while validation of these models also requires reliable measurement tools to compare model predictions with the measured behaviour of the system. This review and discussion is therefore dedicated to the modelling of HSWG processes as well as measurements required for the model calibration/validation (not quality measurements in general). Focus is hereby on the existing intention of the pharmaceutical sector to move from batch to continuous production (granulation). Section 2 summarises the current state of the art of high-shear batch granulation specific modelling approaches and process measurement techniques. Next to the review, a critical discussion is provided in section 3 highlighting current knowledge gaps and potentially interesting new research directions of modelling and measurement tools for the efficient adoption of continuous TSG 




Figure 3: Knowledge development framework using modelling and measurement tools

1 systems.

\section{Current modelling and related measurement tools for HSWG}

It is generally accepted that the availability of mathematical process model(s) and suitable measurement device(s) for a pharmaceutical process when successfully interlinked (i.e. performing proper model calibration and validation), can lead to functional and robust knowledge based control of process and product quality [16]. Unfortunately, many of the parameters used in HSWG models are difficult to measure in the field, yet they have a substantial impact on the performance of the granulation models. Most of the granulation modelling based analyses are often understood to be carried out under default parameter values or best-guessed values. This is mainly due to either difficulties in experimental data collection or lack of suitable measurement tool for the simulation model calibration and validation. it is therefore very relevant to discuss potential options among available mathematical modelling practices and related measurement technologies. Not properly calibrated and validated models later when tested result in unrealistic estimates of the impact of any change in process condition. Thus, calibration and validation of simulation models are crucial steps in assessing their value in granulation process modelling. Adjustments or tuning in model parameters through calibration are necessary to improve the ability of granulation models to replicate process measured conditions and properly reflect the impact of any change in it (Figure 3). This section of the review comprises the currently reported developments in modelling practices and related measurement tools of the batch HSWG in order to illustrate the degree to which this potential has been exploited thus far. This overview then allows identifying potential gaps and developing a list of unexplored possibilities for facing the challenges (Table 1) inherent to the continuous form of HSWG. 


\subsection{Mathematical modelling of $H S W G$}

The first step in development of first-principle models for the granulation processes is to understand the mechanisms of the granulation process at micro or particle-level. If the particle-level mechanisms are not understood to a certain extent, an appropriate modelling of the complete system at meso- or macro-scale does not have a fair chance of success. The particle-level mechanisms for some of the key processes that may take place during HSWG have been reviewed by Iveson et al. [18] and respective models are summarised in Table 4. As not all particle-level mechanisms are well understood (e.g. wetting and nucleation), some empirical expressions are included in the model (leading to so-called semi-empirical or "grey box" models) in order to allow simulation of the granulation system.

Although the underlying mechanisms of the granulation process are still being investigated, especially in case of TSG where such detailed knowledge is not yet established [3], it is well motivated to model the system at meso- or macro-scale such as to exploit the benefits of process system engineering (PSE) methods and tools [16]. PSE tools rely on domain knowledge and mathematical and experimental techniques to build computer models which relate the change at a molecular level to macro-scale system performance in order to develop and optimise the system. The necessity of a multi-scale approach towards granulation process optimisation, monitoring and control has been documented in detail by Cameron and Wang [19].

Several approaches are adopted for macro-scale modelling of granulation processes as overviewed in table 5. Two main modelling approaches mostly used for HSWG processes are (1) population balance modelling (PBM); and (2) the discrete element method (DEM). The aim of both approaches is to model the mechanisms (discussed in Table 4) and predict the resulting steady-state distribution characteristics such as GSD, moisture content etc. Some hybrid approaches are discussed as well to demonstrate the benefit of linking one modelling approach to another one.

\subsubsection{Population balance modelling}

A PBM provides a statistical description of a system of particles that are undergoing size change mechanisms leading to size increase and/or reduction. They have numerous applications in the engineering sciences apart from granulation, for example in the field of crystallisation, coagulation of aerosols, polymerisation, and cell growth to name but a few. The balance is solved to obtain statistical properties, such as the GSD. In a HSWG process, assuming that the aggregation depends only on particle size, where size is a continuous variable, the general form of a population balance equation (PBE) for a well-mixed system is given as [20]:

$$
\frac{\partial n}{\partial t}(x, t)+\frac{\partial}{\partial x}\left[n \frac{d x}{d t}\right](x, t)=\Re_{\text {birth }}(x, t)-\Re_{\text {death }}(x, t)
$$

where $\frac{\partial}{\partial x}\left[n \frac{d x}{d t}\right](x, t)$ represents the continuous growth or attrition loss along the internal coordinate of the particle diameter, $\Re_{\text {birth }}$ and $\Re_{\text {death }}$ represent the net formation and depletion rates of particles resulting from 
2 and breakage explicitly, the PBM becomes [21]:

$$
\begin{aligned}
\frac{\partial n}{\partial t}(x, t)+\frac{\partial}{\partial x}\left[n \frac{d x}{d t}\right](x, t)= & \frac{1}{2} \int_{0}^{x} \beta(x-y, y) n(x-y, t) n(y, t) d y-n(x, t) \int_{0}^{\infty} \beta(x, y) n(y, t) d y \\
& +\int_{0}^{\infty} K_{\text {break }}(y) \zeta_{\text {break }}(y, x-y) n(y, t) d y-K_{\text {break }}(x) n(x, t)
\end{aligned}
$$

$$
\begin{aligned}
\frac{\partial}{\partial t} n(x, z, t)+\frac{\partial}{\partial x}\left[n \frac{d x}{d t}\right](x, z, t)= & \frac{1}{2} \int_{0}^{x} \beta(x-y, y) n(x-y, z, t) n(y, z, t) d y \\
& -n(x, z, t) \int_{0}^{\infty} \beta(x, y) n(y, z, t) d y+\int_{0}^{\infty} K_{\text {break }}(y) \zeta_{\text {break }}(y, x-y) n(y, z, t) d y \\
& -K_{\text {break }}(x) n(x, z, t)-\frac{\partial}{\partial z}[\dot{Z} n(x, z, t)]
\end{aligned}
$$

Equation 2 is an integro-partial differential equation, and an analytical solution can only be found for simple $\beta(x, y)$ and $K_{\text {break }}(x, y)$ functions. However, these generally correspond to non-physical cases. Thus, numerical approaches are required for more complex functions describing real-life systems.

\section{Population balance model development for a continuous system}

Granulation operations in the pharmaceutical industry are mostly performed as batch processes and therefore, most modelling studies with respect to pharmaceutical granulation have focused on batch processes. In equation 2, there is no spatial coordinate included in the model because a well-mixed system is assumed (i.e. no spatial variation). However, the modelling of a continuous system involves both internal and external (spatial) coordinates, which are specified in the PBE to capture this spatial variation [22], as given in equation 3 :

where, the spatial velocity in the external coordinate is defined as $\dot{Z}=d z / d t$. Thus, a 1-D continuous PBE provides a description of the evolution of one evolving property of particles and the conservation of their internal attributes. Heinrich et al. [23] discussed the modelling of continuous fluidized-bed spray granulation with recycle, which predicts the occurrence of both oscillatory steady-states as well as unique steady states in these processes. The spatio-temporal variation has also been identified in batch-scale granulators as the intensity of different granulation mechanisms varies between specific zones of the equipment based on the conditions prevailing in a granulator [24-27]. The particle flow pattern and their visit frequency through the specific granulator zone during the operation has been defined numerically with the use of computational fluid dynamics ( CFD) and DEM. For instance, a CFD-PBM approach was used in the case of diluted particles/droplets dispersed in a fluid [24, 25]. The DEM can also be combined with the PBM when a dense 
flow of particles is considered [26, 27]. Freireich et al. used this technique for large particles blended in a dual-axis mixer in the context of coating applications [26]. The domain was separated into two compartments to represent the spray zone and the rest of the particle bed. Only layering granulation and particle coating were investigated. Particle aggregation and breakage mechanisms were not considered in the study. In case of HSWG, the PBM-DEM approach is most suitable. However, no such study was presented for HSWG until recently when Bouffard et al. demonstrated a PBM-DEM hybrid model where the particle flow was accounted for in simulation by a compartmental model, which was implemented in the PBM considering particle aggregation or breakage mechanisms [28]. Each compartment was considered perfectly mixed and associated with one or more specific granulation mechanisms. Although less work has been done on continuous granulation for pharmaceuticals, a clear gain of knowledge has been obtained in other chemical industries by adopting such continuous PBE models [29]. In specific, processes such as crystallization and flocculation where the continuous operation is more well-known, PBEs are used extensively [30-34].

\section{Multi-dimensional Population Balance Models}

The accurate modelling of pharmaceutical granulation processes involving a multi-component system requires the consideration of multi-dimensional PBEs. Along with granule size, granulation liquid content has a major effect on granule growth. Several studies demonstrate that the amount of liquid directly correlates with the rate of granule growth, due to a larger availability of surface-wet granules with increased liquid dosage $[35,36]$. Similarly, granule porosity is an essential parameter having significant effect on granule growth and breakage behaviour, deformability and strength [36]. Consequently, multi-dimensional PBEs incorporating the effect of such parameters are now frequently being developed [21, 37-41]. A multidimensional PBE can be formulated as:

$$
\begin{aligned}
\frac{\partial}{\partial t} n(m, \varepsilon, w, x, t)+ & \frac{\partial}{\partial m}\left[n \frac{d m}{d t}\right](m, \varepsilon, w, x, t)+\frac{\partial}{\partial \varepsilon}\left[n \frac{d \varepsilon}{d t}\right](m, \varepsilon, w, x, t) \\
& +\frac{\partial}{\partial w}\left[n \frac{d w}{d t}\right](m, \varepsilon, w, x, t)+\frac{\partial}{\partial x}\left[n \frac{d x}{d t}\right](m, \varepsilon, w, x, t)=\Re_{\text {birth }}-\Re_{\text {death }}
\end{aligned}
$$

In recent years, the number and types of multi-dimensional PBEs applied to granulation systems has considerably increased. However, care must be taken to model only the primary mechanisms in multi-dimensional PBEs, as the model may become excessively complex and numerical errors can increase prohibitively leading to inaccurate predictions. A hybrid PBE can be formulated to tackle this challenge. E.g. in an aggregation only model, a two-dimensional population balance can be presented where collision is dependent only on particle size but aggregation is dependent on both particle size and surface wetness (or stickiness). Similarly, Biggs et al. [42] used a pseudo two-dimensional (2-D) PBM that allowed composition on a size-averaged basis to be modelled and coupled to the GSD. Verkoeijen et al. [43] proposed a formulation of the multidimensional PBE, where the particle attributes are re-cast in terms of their individual volumes of solid $(s)$, 
liquid $(l)$ and gas $(g)$. This modelling in terms of its individual volumes enables decoupling of the individual mesoscopic processes (i.e., aggregation, consolidation, etc. in Table 4 ) and one can model a single rate process at a time. The resulting multi-dimensional PBE is thus given as [44]:

$$
\begin{aligned}
& \frac{\partial F}{\partial t}(s, l, g, t)+\frac{\partial}{\partial s}\left(F(s, l, g, t) \frac{d s}{d t}\right)+\frac{\partial}{\partial l}\left(F(s, l, g, t) \frac{d l}{d t}\right) \\
& +\frac{\partial}{\partial g}\left(F(s, l, g, t) \frac{d g}{d t}\right)=\Re_{\text {birth }}(s, l, g, t)-\Re_{\text {death }}(s, l, g, t)
\end{aligned}
$$

4 This formulation has been used extensively due to the mutually exclusive character of the internal coordi5 nates which substantially improves the numerical solution of the model as the rate processes with distinct 6 time constants are segregated [40, 45-47]. Beyond this, it potentially prevents lumping in any of the dimensions due to the heterogeneity of the population distribution with respect to its attributes, which could 8 cause model errors [48].

9 The increase in dimensions of PBEs causes complexities which have been listed by Pinto et al. [21]. Formulation of multi-dimensional so-called rate kernels to include the constitutive relations for the particle-level 1 rate processes is challenging. Similarly, the numerical solution of such model equations is complicated and 2 computationally expensive. Lastly, to ensure wider validity and predictive capability of these models, the 3 development of instrumentation for detailed measurements is required not only at the macroscopic level, 4 but also at the particle level, i.e. at microscopic levels.

\section{Formulation of Kernels}

Kernels contain the most important physics of the involved mechanism, and the development of multidimensional kernels that account for the dependence of the rates on particle properties (i.e., size, liquid content and porosity) requires a thorough understanding of the underlying physics. Some of the important properties of theoretical, experimental and mechanistic kernels which are widely found in literature and used in granulation studies involving aggregation and breakage mechanisms are discussed here to provide an overview.

\section{Aggregation kernels}

The aggregation kernel is essentially a measure of how frequent and successful a binary collision of two particles is. It is affected by two major factors: (1) collision probability of the specified pair of particles (related to transport); (2) successful aggregation or rebounding after collision (related to short range effects) [49]. The discrete variant of the aggregation kernel $\beta_{i, j}(t)$ among the classes $i$ and $j$ is defined as the product of the collision frequency $\beta_{i, j}$ of the particles and the aggregation efficiency, $\beta_{0}(t)$ i.e.,

$$
\beta_{i, j}(t)=\beta_{0}(t) \cdot \beta_{i, j}
$$


The first factor, $\beta_{0}(t)$, depends on various process parameters such as kinetic energies of particles, their path and collision orientation, particle characteristics (e.g. mechanical properties and surface structure), viscous dissipation between approaching particles and inter-particle forces, and granulation liquid properties, aggregation mechanism, etc. Generally, $\beta_{0}(t)$ is assumed to remain constant throughout the experiment and is size independent [50]. The collision frequency $\beta_{i, j}$ is a function of particle size, gas velocity, system temperature, etc. Determination of the collision frequency function is a complex task in most of the models and it is very difficult to determine it from experimental data. However, an alternative way of retrieving the kernels based on experimental data is to solve the inverse problem [51, 52]. Braumann and Kraft studied the inverse problem occurring in a multidimensional population balance model describing granulation employing linear response surfaces [39] and second order response surfaces [53]. There are different collision frequency functions for kernels available in the literature based on theoretical, empirical and experimental calculations and observations (Table 6). These kernels have evolved from empirical to mechanistic and further to multidimensionality.

\section{Breakage kernel}

Evidently, the breakage functions of a PBM (eq. 2) are the breakage kernel, $K_{b r e a k}(x, y)$, and the probability distribution function, $\zeta_{\text {break }}(y)$. Compared to the aggregation kernel, research on the breakage kernels is still in its infancy. The kernels proposed in literature belong to two major categories: the algorithmic breakage kernels and the mechanistic breakage kernels [54]. To avoid the breakage kernel in high-shear granulation models, Sanders et al. [55] and Biggs et al. [42] tried to model breakage as a negative aggregation rate process, by reporting a reduced aggregation rate constant. However, this approach had serious flaws, as aggregation is a second order rate process and breakage is a first order rate process and will not succeed without considering any physical basis [56]. Many attempts to model the breakage kernel have been made over the years (Table 7).

The mechanistic breakage functions which are based on physicochemical models of the breakage process are usually very complicated and even hard to be approximated as simpler homogeneous functions [46, 56]. However, almost all the algorithmic breakage functions are homogeneous and thus have been used extensively in the study of the general properties of the fragmentation equation in physics literature [54]. Dhanarajan and Bandyopadhyay [57] presented an energy-based model for HSWG processes, whereby the extent of granule breakage was considered to be directly proportional to the impact-energy and inversely proportional to granule strength. While their model simulation showed a close association with the experimental results for the granulation recipe, it missed a rigorous physical basis by assuming that kinetic energy was solely a function of mass, and not velocity and that all collisions were elastic (neglecting loss of kinetic energy due to inelasticity). Furthermore, the granule strength was primarily considered as a function of granulation liquid content, without taking the effect of liquid properties such as viscosity, surface tension and contact- 
angle into account. Recently, a mechanistic breakage kernel for a high-shear mixer granulator was presented by Ramachandran and co-workers [46]. The derived kernel is a function of several important material properties (i.e., powder and granulation liquid properties) and process/design parameters, which influence the intermittent and end-point properties of the granule.

\subsubsection{Solution of one- and multi-dimensional PBEs}

The derivation of a numerical scheme for efficient and accurate solution of population balance problems is quite difficult due to the association of integral terms with the hyperbolic equation. However, during the past few decades, many researchers have solved PBEs and as a result different numerical schemes have been developed. Several reviews of these schemes are available and have been also compared in terms of accuracy of calculation and required computational time [20, 22, 58-60]. The solution of a multi-dimensional problem is both difficult and computationally very expensive and therefore there are two different approaches to deal with an n-dimensional PBE: (1) computation on a complete model with computationally efficient techniques and (2) computation on a reduced model.

\section{Solving the complete PBE}

During the past few decades, a number of methods have been developed for numerical solution of PBEs. Among these methods, some are used to simulate the evolution of moments, while others are used to solve for the GSD explicitly. Methods available to solve for moments include various quadrature methods of moments [61-64]. On the other hand, to solve for GSD explicitly available methods include, methods of characteristics [34, 65], Monte Carlo techniques, [36, 66, 67] and discretised methods like, the fixedpivot (FP) method [32, 34], the moving pivot method [33], the lCATcell average techniquecell average technique (CAT) [30, 68], the hierarchical two-tier method [41, 69], the two-level discretisation algorithm [21], the finite volume method (FVM), the finite element method, finite-volume high-resolution method [70, 71] and most recently the Lattice-Boltzmann method [72].

Although most of the conventional numerical techniques have been applied to multi-dimensional PBEs in various studies, $[37,38,40,41,73]$ the increase in computational load with increase in dimensions of the PBEs presents the challenge of obtaining the solution in process relevant time frames. Consequently, solution methods such as Monte Carlo techniques which are computationally more efficient have received most attention [36, 39, 60, 73]. In a comparison study of three numerical methodologies, i.e., direct solution by discretisation, constant-number Monte Carlo (cNMC) and the direct quadrature method of moments (DQMOM), to a two-component aggregation PBE with a kernel that depends both on size and composition, Marshall Jr. et al. [60] showed that the cNMC method is in close agreement with the direct discrete solution in all cases which assumed to provide exact solutions however being computationally very expensive. The DQMOM method has been found to be highly accurate when the kernel is independent of composition. 
When the kernel is composition dependent, accuracy of this method was found to be variable and very sensitive to the details of the initial distribution.

Due to the inherent nature of discretised methods to preserve the properties of the distribution, extensive work has been done particularly on the FP method and the CAT, which have been extended later to improve the applicability with increase in number of dimensions $[30,37,74,75]$. To compare these developments by solving two-dimensional aggregation PBEs, Kumar et al. [76] found that the CAT is quite a stable scheme as compared to the FP method and improves the results both for the number density and for the higher moments. Thus, the formulation of the CAT can technically be extended to more than two-dimensional problems but it can be computationally very expensive which is also evident by the results shown by Barrasso and Ramachandran [47].

The overall outcome of such comparison studies are always a compromise between prediction accuracy and speed. To account for more physical parameters in PBM and apply mechanistic kernels based on a Lagrangian model (such as from DEM) the direct solution methods based on Eulerian coordinates are known to be computationally more efficient. As such technique is not developed, discrete stochastic methods based on Monte Carlo techniques still have an advantage on efficiency along with other benefits addressed earlier.

\section{Reduced order multi-dimensional PBE}

For each additional component used in the pharmaceutical formulation, a new dimension shall in principle be added to the PBM. While this approach may work in theory, its increased computation time and complexity limits its applicability. A practically more feasible strategy is that a high-dimensional PBM can be reduced to several simpler models of lower dimension $[42,77,78]$. In a reduced order model, one or more granule characteristics are lumped into the remaining distributions. For example, a two-dimensional model given by

$$
\begin{aligned}
\frac{\partial}{\partial t} f\left(v, v_{L}, t\right)= & \frac{1}{2} \int_{0}^{v} \int_{0}^{\min \left(v_{L}, v-\varepsilon\right)} \beta\left(v-\varepsilon, v_{L}-\gamma, \varepsilon, \gamma\right) f\left(v-\varepsilon, v_{L}-\gamma, t\right) f(\varepsilon, \gamma, t) d \varepsilon d \gamma \\
& -f\left(v, v_{L}, t\right) \int_{0}^{\infty} \int_{0}^{\varepsilon} \beta\left(v, v_{L}, \varepsilon, \gamma\right) f(\varepsilon, \gamma, t) d \varepsilon d \gamma
\end{aligned}
$$

$23 \quad$ Whis

where, the granule is represented by total volume, $v=v_{s}+v_{L}$, and $v_{L}$, volume of the liquid. In this 2-D model, the coordinate space $x=\left(v, v_{L}\right)$ can be reduced to two 1-D equations, by assuming that all of the granules of a given size have the same liquid content, as follows [42]:

$$
\frac{\partial}{\partial t} n(v, t)=\frac{1}{2} \int_{0}^{v} \beta\left(v-v^{\prime}, v\right) n\left(v-v^{\prime}, t\right) n\left(v^{\prime}, t\right) d v^{\prime}-n(v, t) \int_{0}^{\infty} \beta\left(v, v^{\prime}\right) n\left(v^{\prime}, t\right) d v
$$




$$
\frac{\partial}{\partial t} M(v, t)=\frac{1}{2} \int_{0}^{v} \beta\left(v-v^{\prime}, v\right) M\left(v-v^{\prime}, t\right) n\left(v^{\prime}, t\right) d v^{\prime}-M(v, t) \int_{0}^{\infty} \beta\left(v, v^{\prime}\right) n\left(v^{\prime}, t\right) d v
$$

Reduced order models simplify the solution of the model, but they are not exactly equivalent to the full model. Hounslow et al. [77] warned against model order reduction for parameters that influence the rates, as it is expected that these rates are a function of composition such as the liquid content within individual granules. Recently, Barrasso and Ramachandran [47] compared a full 4-D model with a combination of lower-dimensional models resulting from a model reduction using the lumped parameter technique, and showed that although the 3-D model with a lumped solid volume yielded results similar to the full model, it showed differences in the distribution of composition with diameter. This drawback is probably most relevant since the composition is important in multi-component granulation processes with respect to pharmaceutical production.

Rigorous calibration and validation of the PBM is key for scientific and commercial acceptance, but is equally challenging due to high variation in the process output. In the modelling of granulation processes discussed so far, the inverse problem is often unavoidable. Therefore, experiments have to be carried out in order to identify and measure the unknown model parameters, e.g. aggregation rate constants [51-53, 73]. Such parameter estimation is normally done through fitting the model to the experimental data obtained from measurement of macroscopic quantities and will be discussed in section 2.2. Once these model parameters are validated, the model can be employed for predicting the granulation process using the system under consideration.

\subsubsection{Discrete Element Method}

Whilst the majority of granulation research at the meso- and macro-scales has been performed using PBM, the DEM approach bridges the gap between micro- and meso-scales [78-82]. There are two main classes of discrete element methods which have been used in granulation modelling: hard-sphere methods and soft-sphere methods, each with their state of development, relative advantages and drawbacks (Table 8). These approaches have been applied and reviewed by several researchers [79, 82-85], and a wide variety of different granulation systems have been modelled. The hard-sphere method assumes that particles are rigid so that collisions are instantaneous and binary, which is not valid in highly dense HSWG systems where particle contacts are long-lasting, have low coefficients of restitutions and involve multiple particles. In the soft-sphere model, on the contrary, contacts are not assumed to be instantaneous and more than one contact at a time is possible.

Developed by Cundall and Strack [86], soft-sphere DEM has been preferably used in granulation modelling where positions, velocities, accelerations and the trajectories of every particle are tracked by solving Newton's second law of motion in a particulate assembly individually. This method allows deformation of 


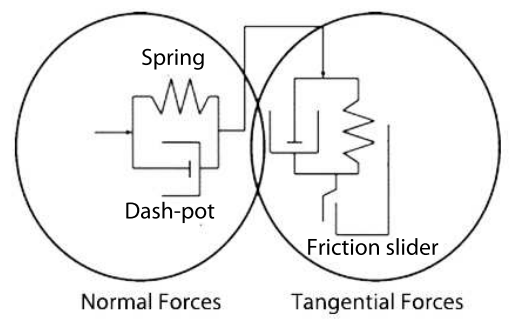

Figure 4: Representation of normal and tangential contact forces using a spring, dash-pot and slider approach [86].

$$
m_{i} \frac{d v_{i}}{d t}=m \vec{g}+\vec{F}_{p}+\vec{F}_{w}
$$

$$
\mathrm{I}_{i} \frac{d \omega_{i}}{d t}=\vec{M}_{p}+\vec{M}_{w}
$$

particles which is modelled as an overlap of the particles in a collision event. The forces are expressed with the use of a spring, dash-pot and slider which separate forces into normal and tangential forces as shown in Figure 4. The linear and angular momentum equations for each granule in the granulator are given by

The sum of applied forces includes contributions from contact forces resulting from particle-particle and particle-wall collisions and the gravitational force $m \vec{g}$. The viscous drag force is often assumed negligible in high-shear dense granular systems. The associated moment is the sum of the moments of particle-particle $\left(\vec{M}_{p}\right)$ and particle-wall $\left(\vec{M}_{w}\right)$ collisions.

DEM models have some advantages over PBM in terms of ability to define complex particle-particle interaction laws and to allow distribution of properties, for instance, distribution of sizes or varying material properties to model a mixture of various components. Since powder characteristics and essential hydrodynamic parameters regarding liquid-solid interaction, particle mixing and segregation are lumped into the kinetic rate constants, PBM cannot be applied for a-priori process design, unlike DEM. Moreover, DEM can be used to calculate many particle-scale quantities of interest such as local concentrations and particle phase stresses, as well as to examine particle-level phenomena such as segregation or aggregation, as the location of the particles along with the velocity field is known throughout the simulation [79, 81]. However, this all comes at a high computational cost, which is due to the small integration time-step used in DEM, so that particles only have contact with their nearest neighbours. Overlap between particles is assumed to be small in comparison to their size. Since this approach demands significant computational power, DEM cannot handle a very large number of particles which are present in high shear granulation. However, due to the steadily increasing speed of computer hardware and codes with parallel processing capabilities, the size 
of systems that can be modelled with DEM is continuously increasing. Some recent DEM models simulate systems in the order of a couple of hundred thousand till more than a million particles [78, 87] and, recently the DEM method has been used in scale-up studies [81]. Also, in a study for continuous HSWG using TSG the DEM has been very valuable to predict the velocity profile of the powder materials which was then used to calculate the residence time distribution (RTD) in a twin-screw granulator, which is otherwise very hard to measure [88]. Talu et al. [89] modelled aggregation and breakage in 2D shear flow of a mixture of "wet" and "dry" particles showing the effect of the amount of granulation liquid, the Stokes number, and the capillary number on the GSD. Muguruma et al. [90] modelled a centrifugal tumbling granulator where the liquid was uniformly distributed. The resulting velocity profiles were in agreement with experimental data using glass beads of the same size. Mishra et al. [91] examined the aggregation of particulates in a rotary drum with a model that included a spray zone and also considered the drying of particles. The first significant effort for DEM modelling for HSWG systems was undertaken by Gantt and Gatzke [79], which incorporated three key mechanisms of granulation, i.e. aggregation, consolidation, and breakage. The rates of each mechanism were directly simulated and integrated to model a dynamic GSD. The results from this DEM model were in good agreement with other approaches such as PBM along with additional capability to model dynamic operating conditions. Later Gantt et al. [78] also used the hybrid approach where a DEM model with periodic boundary conditions was used to represent flow in a high-shear granulator. The particle collision statistics compiled by the DEM simulation were used to develop an aggregation kernel, which was used with a Monte Carlo method to solve multidimensional PBEs. Good agreement with experiments was observed in terms of velocity flow fields. Recently, Liu et al. [85] investigated the transverse mixing of wet particles in a rotating drum to investigate the effects of liquid surface tension, drum rotation speed and the filling level on particle mixing. DEM was proposed to estimate the circulation periods at different streamlines which were comparable with the simulation results, thus providing a general method to predict mixing performance in the transverse plane. Granulation in fluidized beds has also been modelled using DEM by several researchers [92-94].

While these studies indicate a trend of increasingly applying DEM as tool to simulate dense particle systems, there has been no satisfactory effort to calibrate the DEM in order to be able to reproduce the complicated granulation process and deploy the versatility of DEM. The calibration process in DEM is a typical inverse problem similar to PBM and is usually carried out based on data from laboratory test results, which are compared with simulation results for the identified parameters in terms of change in shape, size, strength etc. However, compared to PBM, the calibration and validation of DEM models do not appear to be as rigorous and the procedures certainly are not as well defined. There are several micro-scale related parameters involved in determining the macro-scale behaviour for granules. For calibration of granulation processes incorporation of micro-scale material properties such as wet granule yield strength, Young's modulus, and asperity size are required along with material flow characteristics such as velocity and shear fields. Efforts 
to develop a calibration and validation procedure for DEM based on experimental data have already been taken in other processes (e.g. for discharge flow in silos [95] and mixing in the turbula mixer [96]). However, despite the fact that a number of measurement tools are already in place for HSWG (section 2.2), development of a detailed calibration and validation procedure for DEM applied to HSWG will require several other measurement tools to be developed as well (section 2.2) to achieve sufficient process understanding.

\subsection{Measurement techniques}

The literature reveals that a wide variety of measurement techniques have been applied to measure and understand the critical process parameters (CPPs), critical quality attributes (CQAs) and their relationships in HSWG. The most frequently reported measurement techniques for HSWG are overviewed in Table 9. This table furthermore highlights for which type of model the measured value could be useful as calibration and validation input. Although there is sparse work on the model calibration and validation, some of the available studies are cited for reference. Finally, the capability of each measurement technique for realtime monitoring and, hence its applicability to continuous granulation processes is indicated. Discussions on validation studies have appeared considerably more frequently in the literature than those regarding calibration. Most validation studies for granulation models have been qualitative and rely on data from visualisation of experimental flows where the observations are used to validate granulation models for highshear granulators $[46,55,97,98]$. The qualitative studies have primarily focused on model fitting of endpoint determination parameters such as granule size and their physical properties. As the in-line measurements during HSWG are very complex and challenging due to the high shear conditions these studies applied mostly offline measurement tools. However, several in-line measurement techniques for determination of the GSD have been recently developed as well. Focused beam reflectance measurement (FBRM) and Parsum (Spatial Filtering Velocimetry) are designed to directly track real-time changes in particle size and distribution in the process [14]. Betz et al. [99] have described a technique for measuring tensile strength of granules, in addition to power consumption measurement, to facilitate optimal endpoint determination. Also, near-infra red spectroscopy (NIR) and Raman spectroscopy have shown to be promising due to their ability to provide both chemical as well as physical information such as moisture content and particle size of the samples while monitoring in-line [100]. Other data handling techniques reported in the literature include the use of neural networks to describe and predict the behaviour of the wet granulation [101] or control of the endpoint in HSWG on the basis of the data acquired with a high-speed imaging system [102] and audible acoustic emission (AE) piezoelectric sensors. However, extraction of useful information often requires chemometric model development and validation [103]. All these techniques have shown to be promising for application in HSWG, and eventually they can be used to validate various conceptual models of the process. However, each process analyser has its own limitations hampering its application as an accurate in-line monitoring and endpoint determination tool (see table 9). Therefore, adaptations to the various analysers are now 
being made to solve some of these issues. For example, in new equipment set-ups for the HSWG, the air exhaust has been used to suspend the AE sensor, which eliminates the challenge of maintaining consistent contact between the sensor and the vessel. This allows measurement of a variety of particle interactions instead of localized contacts between the particles in the granulator [104]. Similarly, the fouling issues of the FBRM probe have been solved by providing a pressurized air activated mechanical scraper on the sapphire measurement window to prevent powder from sticking. The effectiveness of the scraper has already been proven in the harsh conditions of a high shear granulator [105].

The visualization of experimental flows during validation studies is very challenging due to the opacity of bulk solids which limits the applicability of visualization techniques. Tomographic techniques have also been developed towards validation of 3D granular systems. These techniques are non-intrusive and are not hindered by the opacity of solids. Therefore, they are used to probe the internal microstructure and particle velocities within 3D systems. Nuclear magnetic resonance (NMR) has been used for validation of a long rotating cylinder [106] and the packing of particulates has been examined using X-ray micro-tomography [107]. Nilpawar et al. applied an optical technique which is known as Particle Image Velocimetry (PIV), where the powder surface provides the texture for determination of surface velocities [108]. The shortcoming of PIV in terms of its capability to interrogate only the powder surface, has been solved by application of the Positron Emission Particle Tracking (PEPT) technique which provides an excellent means to interrogate the powder flow patterns in wet granulation [109]. There are still some challenges as it is difficult to obtain spatial highresolution data through PEPT and also the temporal averaging required makes tracking of the changes in bulk motion during a granulation process very difficult [110]. However, such developments are very important as they will aid in obtaining better process visualisation and gaining deeper process knowledge and thus they are potentially useful to support the development of strategies for achieving process consistency and improved control in the context of PAT applications.

\section{Industrial needs and opportunities for continuous HSWG modelling and measurements}

Despite the large amount of research that has been done on modelling and measuring the granulation process, much of the work done in this area is still far from application in the pharmaceutical industry. This is partly due to the fact that the granulation studies have been usually approached from either a process engineering (modelling) or a pharmaceutical sciences (measurements) point of view (see figure 3). To have more insight in an optimal granulation process both disciplines have to be integrated. An increased knowledge about rate processes, their interaction and quantification by advanced measurement tools, along with model refinement are required in order to improve the prediction of the process state in a continuous system. This will also help in establishing significant process understanding required in order to successfully shift towards continuous processing in solid dosage manufacturing. Continuous HSWG is performed 
using TSG, characterized by a modular screw profile including a sequence of different screw elements with various shapes, orientation and functions. Because the residence time is very short in TSG, in general, it is possible to achieve a quasi steady state operation in a few minutes from the start. This state is measured in terms of parameters such as steady torque, stable temperatures, and an acceptable granule quality. Although a stabilization period is needed to reach steady-state conditions the granules and tablets produced during quasi-steady state operation were reported to be within specifications [111]. Key independent process variables of the HSWG process using TSG include screw configuration, screw speed, temperature and locations for liquid feed. The key dependent process variables are feed rates of the formulation powder, granulation liquid feed rate and motor torque. The screw design influences the granulation characteristics and the overall processability for a given formulation, i.e. the achievable dry powder blend throughput. For a given screw design and screw speed, the maximum powder feed rate is defined by the rate at which the torque is $80 \%$ of the manufacturer-recommended limiting torque [112]. The maximum liquid feed rate is defined depending on the moisture-carrying capacity of the formulation powder blend.

From a process technology perspective, a TSG is often divided into different zones, e.g., feed (twin screw granulators are generally fed from external feeders), wetting, mixing, and others (Figure 5). The processing zones of the TSG are arranged in series, linking each granulation step to the next. Analysing each granulation step in the TSG to a satisfactory degree is only possible when sufficient information on the rheo-kinetic characteristics (such as apparent viscosity) of the granulation mixture is available. However, providing these data is very difficult, particularly in the zone with considerable change in phases (e.g. intrinsic moisture in granules gets squeezed out in the kneading zone). The modular structure complicates the process design as the processing zones are not just governed by the screw profile only but also by factors such as the critical moisture content (solid to liquid ratio) of the particle required for aggregation to occur. This reinforces the need to resort to process modelling and real-time measurements for development of improved process understanding. To understand mixing and granulation using different screw configurations, simulation tools could be useful to reduce the amount of experiments needed in industrial practice. By using in-process measurements, combined with a mechanistic modelling framework, one can have a good mechanistic insight into the important parameters of continuous TSG. Also worth mentioning is that extrusion based devices have been applied successfully in plastics and food industries for several decades, and thus a wealth of relevant knowledge on modelling and measurements developed in these industries during the past years can be obtained [113]. However, it is also necessary to identify fundamental differences between a twin-screw extruder and TSG design in terms of other structures such as the die (where pressure is built up for shaping) which is not present in TSG.

\subsection{Needs of modelling TSG}

There are different goals for modelling TSG including improved process knowledge, screw design opti- 


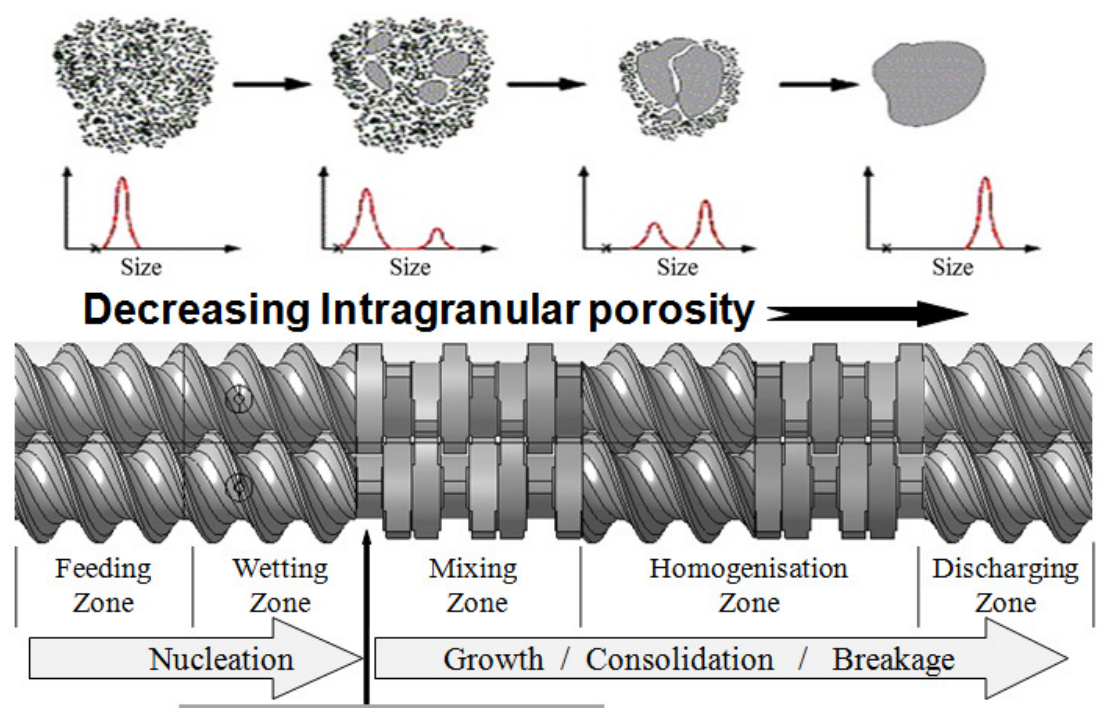

Criticalmoisture content

Figure 5: Interlinked granulation zones in a twin-screw granulator.

1 misation, simulation of individual effects, qualitative studies, or developing online monitoring and control solutions. Several experimental studies have been performed to investigate the effects of key process variables [14, 114, 115], screw configurations [88, 98, 116, 117], and also to make the regime map [118] of the TSG. However, an integrated effort is required for linking new experimental and theoretical findings regarding granulation mechanisms and kinetics into a coherent modelling framework.

6 Results obtained from experimental studies on TSG have indicated that the mechanisms occurring in HSWG using continuous TSG are different from those in batch high shear mixers (HSM), since some of the rate processes given in Table 4 appear to be absent in case of HSWG using continuous TSG [3, 88, 119]. Attributed to the interlinked modular structure of the screws in TSG, this prompts for substantial process understanding both at particle and containing barrel (system) levels, and thus requires a multi-scale approach. Applications of PBM (system level) and DEM (particle level) approaches in granulation have already shown 12 their relevance in modelling batch granulators and mixers. Hence, the opportunity exists to adapt these 13 modelling approaches for appropriate numerical analysis of TSG. However, this adaptation requires consid14 eration of material and equipment properties along with a comprehensive list of process variables and status in such a way that the granule scale model needs to supply the agglomeration kernel to the system scale model [120]. To do so, the granule scale model requires the current GSD and the volumetric hold-up of the granules from the barrel scale. This approach has provided good results in other studies with continuous drum [121] and fluidized bed granulators [50].

Various studies have shown that changes in screw configuration (number and location of transport and 
kneading elements) lead to different granulation GSDs and granule properties $[98,117,118]$. This indicates that although operational regimes are not completely decoupled along the length of the granulator, specific individual rate processes will preferably take place in certain screw regions. Any change to the screw configuration also changes the dominance of one granulation mechanism over the other. Thus the spatio-temporal variation in the macro-environment of the particle dictates the change in the granulation regime in the TSG unlike well-mixed systems. In the current PBM for batch granulation processes, the hydrodynamic parameters are lumped in the rate kernels such that one global equation is applied. However, such assumptions are not valid for TSG with modular structure, and therefore a multi-scale modelling approach is required in which DEM and PBM are combined via a compartmental model (CM) to include the system heterogeneity in the continuous TSG. This approach has already been applied to mixing and coating equipment which involved particle flow patterns having a strong influence on coating distributions [27]. Very recently, a similar approach was applied by Bouffard et al. [28] to rotor based equipment where a CM was used to model particle flow in different zones of the equipment. The PBM based on time-continuous Markov chain received kernels from DEM to simulate particle motion in each compartment. The results from the study proved that such an approach improves the accuracy of the population balance model while the flow pattern of the particles is also successfully modelled. In short, TSG modelling requires the inclusion of spatio-temporal variations occurring within the system.

The process in the granulator is perceived as a spatially one-dimensional process for simple representation, i.e. the individual processes happen along its length axis in different zones. On the other hand, individual effects over the screw cross-section, such as some "fields" are impossible or extremely difficult to measure due to the number of factors (operational parameters and material properties) involved. However, such parameters are required for the reliable prediction of a number of factors such as mixing degree and moisture content of the formulation mixture in the granulation critical region of the barrel. To this purpose, process models with at least a two or ideally a three-dimensional spatial consideration are needed. The accuracy of the model, however, depends on the material data used and the peripheral conditions. The spatial borders of the model (between the two screws and between the screw and barrel) require boundary conditions to be defined and stated.

The co-rotating screws are generally operated continuously, so the focus of modelling is on steady processes for process study. However, in addition to the spatial model dimensions, time may be a key factor in TSG. Therefore, key granulation parameters such as granule size, moisture content, and segregation patterns which exist in the form of a distribution can be a characteristic function of the local residence time and RTD of the granulation powder along with the spatial variation in the process model. A pharmaceutical granulation mixture with two or more main flow components travelling differently can cause segregation leading to quality problems identified in later processing steps. Numerous attempts have been made to model and predict RTD in engineering research using TSE in similar isothermal operation. Gao et al. [122] recently 
reviewed RTD modelling methods including the investigations focused on the co-rotating twin-screw extrusion devices. The application of DEM or CFD simulation provides particle tracking information which can be used to derive the RTD. However, computational data should be validated with experiments before the simulated RTD profile can be applied in practice with confidence [123, 124].

Thus, the possibilities of the modelling approaches are numerous and can be summarized as: (1) Modelling tools are capable of providing information on process values (pressure, power, stress, etc.) with little effort; (2) Application of l-D spatial models are limited to the granulation kinetics and can provide information about the changes in the process values along the screw geometry; (3) For detailed knowledge on the granulation process in a continuous system, "field" variables such as rheological effects have to be linked with kinetic parameters in the process model; (4) The detailed modelling approach can enable a rapid process window definition and will help in determination of the effects of changing screw configuration (or geometry), process values and materials; (5) A CM based approach is required to include the system heterogeneity in the continuous TSG (6) RTD determination requires both computational and experimental efforts so that the simulated RTD profile can be validated.

When making a choice between all the possibilities for constructing a process model, limitations are caused by the fact that modelling and simulation are confined to systems with very specific material properties. Moreover, limited computational power is a major limitation as well. The theory often contains parameters that are not experimentally accessible (such as capillary (surface tension) forces for the aggregation) and this limits its application. Therefore the potential for a successful process modelling study for HSWG in TSG lies either in simpler models with limited applications or in proper planning of modelling studies by (a) defining modelling goals and objectives, (b) determine suitable modelling tool, (c) determining required experimental data, (d) choosing measurement tools to acquire that data and finally (e) apply measured data for model calibration and validation.

\subsection{Tools for measurement of state variables}

There has been a significant development in the measurement techniques for end-point determination parameters as discussed previously (section 2.2). While, many of these currently measured variables are applicable to various modelling approaches as given in Table 9, more analytical methods are needed to measure other internal process characteristics (e.g., degree of mixing, moisture content, shear). The developments in measurement tools thus far primarily focused on measuring variables, which are either quality parameters themselves or indirectly used to determine the quality of granules as discharged product (such as torque, NIR). Fonteyne et al. [14] and Vercruysse et al. [115] have evaluated the CPPs and CQAs influencing the granule characteristics in a continuous granulation using TSG. For mechanistic understanding of the granulation process in TSG and validation of rheo-kinetic models, local information about numerous parameters such as "field" variables, granulation liquid content, filling degree of the barrel and many more 


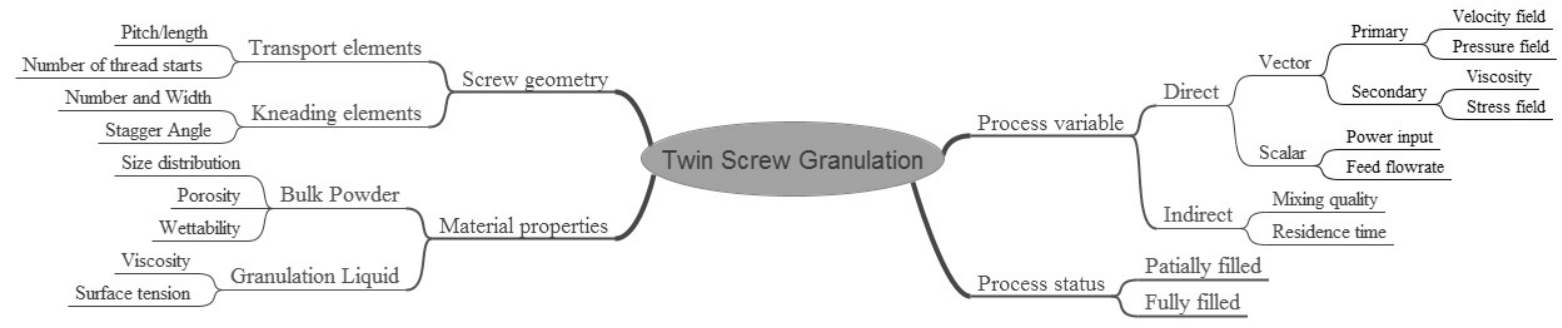

Figure 6: Key parameters for measurement and modelling of a twin-screw granulator.

mentioned in Figure 6 are required to be measured in-line throughout the granulator barrel. However, it is important to note that these measurements are only required in the stage of knowledge development and later on these measurements are not really required as with mechanistic understanding maybe correlations between them and more easily measureable variables can be obtained.

In the current measurement practices there are two general methods applied, those in which material is withdrawn for analysis, and the other in which material remains in the process and the observation is taken from a free surface or from material next to a wall which is transparent [125]. Free surface sampling are only easy in processes containing air and operating close to atmospheric conditions which is not the case in granulation using TSG. Being an opaque multiphase system, several crucial process parameters in TSG such as mixing and filling degree of the barrel which cannot be easily measured and monitored during the granulation are correlated with the mechanical power consumption and in-line dynamic torque of the TSG [126]. However, the real world is 3-dimensional and 0-dimensional measurements such as a torque measurement generally relate to the entire screw, making such measurements not suitable to provide local information. In the plastic and food industries where TSE has been used extensively, such studies have been performed by having small windows in the side of a metal barrel or by using a transparent barrel in combination with probes such as Laser Doppler Anemometers [127, 128]. The other approach consists of flow visualization in a barrel using radioactive particle tracking methods such as PEPT, or imaging techniques such as PIV [129]. The obtained velocity profile in TSG has further been utilized to construct RTD profiles [88] and study the effect of a change in viscosity of the granulation liquid [130]. Several techniques, which are being used in other areas of research, also facing the challenge of opaque multiphase systems need to be investigated. For instance, magnetic resonance imaging (MRI) is capable of examining various systems and processes non-invasively and non-destructively to provide temporal and spatial information through concentration mapping in a TSG [131].

In recent years, considerable attention has been paid to the development of several rapid and nondestructive so called online soft sensing methods to estimate hard-to-measure online quantities through chemometric models. In essence, the core of a soft sensor is the soft sensing model, which on the basis of other measured variables generates a virtual measurement to replace a real sensor measurement [132], for ex- 
ample for a variable that is difficult to measure otherwise. The introduction of PAT has led to a tremendous increase of the number of spectroscopic applications in the pharmaceutical industry. The capability and applications of NIR and Raman spectroscopy to provide both chemical as well as physical information such as moisture content and particle size on a real-time basis using chemometric methods have been discussed in a previous section on measurement techniques. Soft sensors based on partial least squares (PLS) regression or principal component analysis (PCA) are often preferred, since these methods are well-known in the pharmaceutical industry which facilitates validation [133]. Nevertheless, it has been shown that a number of chemometric methods can effectively be used to extract relevant information; their application needs more investigation before introduction for field application. With the development of models of the underlying processes in TSG, preferably a model involving in-depth knowledge of the underlying physical phenomena of the process, prospects for application of soft sensors will improve.

The possibilities of the measurement approaches can be summarized as: (1) 0-dimensional measurements such as torque are easy to implement, but do not provide local information required for a detailed process understanding. (2) Higher dimensional measurements are hard-to-measure on-line but mandatory. (3) Obtaining detailed information about the "field" variables in the screw cross-section using flow visualization in a barrel is possible now. Techniques such as PEPT which can provide detailed quantitative information on internal flow-patterns have a great role to play. (4) Developments in other research areas, also facing the challenge of opaque multiphase systems, should be explored. (5) Application of soft sensing methods has shown potential, but their application needs more investigation before introduction of soft sensors for field application.

\section{Conclusions and perspectives}

This study provides a critical analysis of the current state of modelling and measurement practices in HSWG. It suggests paths forward for the development of models and measurement devices for continuous wet granulation processes in the pharmaceutical sector. From the current state of HSWG, it has been identified in this paper that:

- A shift from batch to continuous processing is challenging but equally rewarding for the pharmaceutical sector, and continuous wet granulation is an important part of future continuous manufacturing of solid dosage forms.

- A systematic framework and scientific approach is necessary to utilise efficiently the opportunity provided by the regulators to increasingly rely on the science- and risk-based holistic development of processes and products for commercialisation.

- First-principles and data-driven modelling approaches have great joint prospects and can play an important role in process design, optimisation and control of critical quality parameters in pharma- 
$28 \quad(s, l, g)$ ceutical granulation, but they require a high degree of reliability and development to achieve the target of simulating and investigating real-time control of quality for unit operations such as granulation.

- The available modelling methods show performance limitations as the dimensions of the model increase. This has motivated the need to develop more reliable and computationally efficient numerical methods to provide solutions which can be applied for online model based control.

- Furthermore, rigorous calibration and validation is required for the granulation models to more accurately represent field measured granulation conditions.

The future requirements and developments in modelling and measurement methodologies for implementation of continuous wet granulation in the pharmaceutical sector therefore are:

- The modular structure of the twin-screw granulator is a central issue to be captured in the modelling and measurement techniques applied to the TSG. Understanding the changes in the process values along the screw geometry requires higher dimensional modelling and in-process measurements providing local information.

- A single simple model cannot predict the complex granulation behaviour with shifting granulation regimes. Therefore, different parts of the granulation process should be described by different mechanistically based structural models.

- Although simulation substantially increases the understanding of the processes involved, not all process steps of the TSG can be modelled due to the high computational burden.

- The main challenge in the area of TSG exists in the development of new measurement techniques, which are able to measure the fundamental granule properties, preferably in situ.

- Following extensive research conducted on software sensor technology in the last few years, also in other related fields facing the challenge of opaque multiphase system, it becomes more and more attractive for the industry to use software sensors in real applications.

\section{Acknowledgements}

Financial support for this research from the BOF (Bijzonder Onderzoeksfonds Universiteit Gent, Research Fund Ghent University) is gratefully acknowledged.

\section{List of Abbreviations}

vector representing solid, liquid, and gas volumes of a granule 


\begin{tabular}{|c|c|c|}
\hline 1 & $\beta(x, y)$ & aggregation kernel \\
\hline 2 & $\delta$ & Delta-Dirac function \\
\hline 3 & $\dot{Z}$ & spatial velocity in the external coordinate \\
\hline 4 & $\mu$ & liquid viscosity \\
\hline 5 & $\theta$ & solid-liquid contact angle \\
\hline 6 & $\varepsilon$ & porosity \\
\hline 7 & $F(s, l, g, t)$ & population density of a granule at time, $t$ \\
\hline 8 & $l$ & size of particles \\
\hline 9 & $m$ & total mass of the granule particle \\
\hline 10 & $M(v, t)$ & mass of granulation liquid in the size range \\
\hline 11 & $n(x, t)$ & number distribution of particles \\
\hline 12 & $w$ & fractional granulation liquid content \\
\hline 13 & $x$ & scalar-state variable that represents particle size \\
\hline 14 & $\gamma_{L V}$ & surface tension of the liquid \\
\hline 15 & $\tau_{\text {wetting }}$ & theoretical liquid penetration time \\
\hline 16 & $\varepsilon_{S}$ & surface porosity \\
\hline 17 & $\zeta_{\text {break }}(x, y)$ & the probability distribution function \\
\hline 18 & $B^{0}$ & nucleation rate \\
\hline 19 & $B_{a g g}(x)$ & birth rate of particles of size $x$ \\
\hline 20 & $D_{a g g}(x)$ & death rate of particles of size $x$ \\
\hline 21 & $K_{\text {break }}(x)$ & breakage kernel \\
\hline 22 & $l_{0}$ & size of the nuclei \\
\hline 23 & $r_{d}$ & radius of footprint of drop on powder surface \\
\hline 4 & $R_{\text {pore }}$ & effective pore radius based on cylindrical pores \\
\hline
\end{tabular}




\begin{tabular}{|c|c|c|}
\hline 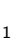 & $V_{0}$ & total volume of drop \\
\hline 2 & $\mathrm{AE}$ & Acoustic emission sensor \\
\hline 3 & CAT & cell average technique \\
\hline 4 & CFD & computational fluid dynamics \\
\hline 5 & $\mathrm{CM}$ & compartmental model \\
\hline 6 & DEM & discrete element method \\
\hline 7 & DIA & Dynamic Image Analysis \\
\hline 8 & FBRM & Focused beam reflectance measurement \\
\hline 9 & FVM & finite volume method \\
\hline 10 & GSD & granule size distribution \\
\hline 11 & HSWG & high-shear wet granulation \\
\hline 12 & $\mathrm{ICH}$ & International Conference on Harmonization \\
\hline 13 & MTR & Mixer Torque Rheometer \\
\hline 14 & NIR & Near-infra red spectroscopy \\
\hline 15 & PAT & process analytical technology \\
\hline 16 & PBE & population balance equation \\
\hline 17 & $\mathrm{PBM}$ & population balance modelling \\
\hline 18 & PEPT & Positron Emission Particle Tracking \\
\hline 19 & PIV & Particle Image Velocimetry \\
\hline 20 & QbD & Quality by Design \\
\hline 21 & RTD & residence time distribution \\
\hline 22 & RTRT & Real Time Release Testing \\
\hline 23 & TSG & twin-screw granulators \\
\hline 24 & US FDA & United States Food and Drug Administration \\
\hline 25 & VoF & Volume of Fluid \\
\hline
\end{tabular}




\section{References}

[1] J. Litster, B. Ennis, The science and engineering of granulation processes, Vol. 15, Springer, 2004.

[2] B. J. Ennis, Theory of Granulation: An Engineering Perspective, in: Handbook of Pharmaceutical Granulation Technology, 2010, pp. 6-58. doi:10.3109/9781616310035.002.

[3] R. M. Dhenge, J. J. Cartwright, M. J. Hounslow, A. D. Salman, Twin screw granulation: Steps in granule growth, Int. J. Pharm. 438 (1-2) (2012) 20-32. doi:10.1016/j.ijpharm.2012.08.049.

[4] Department of Health and Human Services, Food and Drug Administration, PAT Guidance for Industry - Framework for Innovative Pharmaceutical Development, Manufacturing and Quality Assurance, Tech. rep. (2004).

[5] Guideline, ICH Harmonised Tripartite, Pharmaceutical development, Q8 (R2), Tech. rep., Maryland: ICH, Federal Register (2009).

[6] Guideline, ICH Harmonised Tripartite, Quality Risk Management, Tech. rep., ICH Expert Working Group (2005).

[7] Guideline, ICH Harmonised Tripartite, Guidance for Industry: Q10 quality systems approach to pharmaceutical CGMP regulations, Tech. rep., ICH Expert Working Group (2006).

[8] Committee for Medicinal Products for Human Use, Guideline on Real Time Release Testing (formerly Guideline on Parametric Release), Tech. rep., European Medicines Agency (2012).

[9] Guideline, ICH Harmonised Tripartite, Development and Manufacture of Drug Substances, Tech. rep., ICH Expert Working Group (2012).

[10] L. Chablani, M. K. Taylor, A. Mehrotra, P. Rameas, W. C. Stagner, Inline Real-Time Near-Infrared Granule Moisture Measurements of a Continuous Granulation-Drying-Milling Process, AAPS PharmSciTech 12 (4) (2011) $1050-1055$.

[11] S. D. Schaber, D. I. Gerogiorgis, R. Ramachandran, J. M. B. Evans, P. I. Barton, B. L. Trout, Economic analysis of integrated continuous and batch pharmaceutical manufacturing: A case study, Ind. Eng. Chem. Res. 50 (17) (2011) 10083-10092. doi:10.1021/ie2006752.

[12] A. E. Cervera-Padrell, T. Skovby, S. Kiil, R. Gani, K. V. Gernaey, Active pharmaceutical ingredient (API) production involving continuous processes - a process system engineering (PSE)-assisted design framework, Eur. J. Pharm. Biopharm. 82 (2) (2012) 437 - 456. doi:http://dx.doi.org/10.1016/j.ejpb.2012.07.001.

[13] C. Vervaet, J. P. Remon, Continuous granulation in the pharmaceutical industry, Chem. Eng. Sci. 60 (14) (2005) 39493957. doi:10.1016/j.ces.2005.02.028.

[14] M. Fonteyne, J. Vercruysse, D. C. Diaz, D. Gildemyn, C. Vervaet, J. P. Remon, T. D. Beer, Real-time assessment of critical quality attributes of a continuous granulation process, Pharm. Dev. Technol. 18 (1) (2013) 85-97. doi:10.3109/10837450.2011.627869.

[15] A. El Hagrasy, J. Hennenkamp, M. Burke, J. Cartwright, J. Litster, Twin screw wet granulation: Influence of formulation parameters on granule properties and growth behavior, Powder Technol. 238 (2013) $108-115$. doi:10.1016/j.powtec.2012.04.035.

[16] K. V. Gernaey, A. E. Cervera-Padrell, J. M. Woodley, A perspective on PSE in pharmaceutical process development and innovation, Comput. Chem. Eng. 42 (2012) 15-29. doi:10.1016/j.compchemeng.2012.02.022.

[17] M. T. am Ende, R. Bharadwaj, S. Garcia-Munoz, W. Ketterhagen, A. Prpich, P. Doshi, Process Modeling Techniques and Applications for Solid Oral Drug Products, John Wiley \& Sons, Inc., 2010, pp. 633-662. doi:10.1002/9780470882221.ch34.

[18] S. M. Iveson, J. D. Litster, K. Hapgood, B. J. Ennis, Nucleation, growth and breakage phenomena in agitated wet granulation processes: a review, Powder Technol. 117 (1-2) (2001) 3-39. doi:10.1016/S0032-5910(01)00313-8.

[19] I. T. Cameron, F. Y. Wang, Process systems engineering applied to granulation, in: M. J. H. A.D. Salman, J. P. K. Seville (Eds.), Handbook of Powder Technology, Vol. Volume 11, Elsevier Science B.V., 2007, Ch. Chapter 11, pp. 499-552. doi:10.1016/S0167-3785(07)80046-7. 
[20] D. Ramkrishna, Population balances: Theory and applications to particulate systems in engineering, Academic press, 2000.

[21] M. A. Pinto, C. D. Immanuel, F. J. Doyle, A feasible solution technique for higher-dimensional population balance models, Comput. Chem. Eng. 31 (10) (2007) 1242-1256. doi:10.1016/j.compchemeng.2006.10.016.

[22] I. T. Cameron, F. Y. Wang, C. D. Immanuel, F. Stepanek, Process systems modelling and applications in granulation: A review, Chem. Eng. Sci. 60 (14) (2005) 3723-3750. doi:10.1016/j.ces.2005.02.004.

[23] S. Heinrich, M. Peglow, M. Ihlow, M. Henneberg, L. Mörl, Analysis of the start-up process in continuous fluidized bed spray granulation by population balance modelling, Chem. Eng. Sci. 57 (20) (2002) 4369-4390. doi:10.1016/S00092509(02)00352-4.

[24] C. Drumm, M. M. Attarakih, H.-J. Bart, Coupling of CFD with DPBM for an RDC extractor, Chem. Eng. Sci. 64 (4) (2009) 721-732.

[25] C. Garth, A. Middel, H. Hagen, CFD Simulation of Liquid-Liquid Extraction Columns and Visualization of Eulerian Datasets, in: Visualization of Large and Unstructured Data Sets: Applications in Geospatial Planning, Modeling and Engineering-Proceedings of IRTG 1131 Workshop 2011, Vol. 27, Schloss Dagstuhl-Leibniz-Zentrum fuer Informatik, 2011, pp. 59-70.

[26] B. Freireich, J. Li, J. Litster, C. Wassgren, Incorporating particle flow information from discrete element simulations in population balance models of mixer-coaters, Chem. Eng. Sci. 66 (16) (2011) 3592-3604.

[27] J. Li, B. Freireich, C. Wassgren, J. D. Litster, A general compartment-based population balance model for particle coating and layered granulation, AIChE J. 58 (5) (2012) 1397-1408. doi:10.1002/aic.12678.

[28] J. Bouffard, F. Bertrand, J. Chaouki, A multiscale model for the simulation of granulation in rotor-based equipment, Chem. Eng. Sci. 81 (2012) 106-117. doi:10.1016/j.ces.2012.06.025.

[29] F. Y. Wang, I. T. Cameron, Review and future directions in the modelling and control of continuous drum granulation, Powder Technol. 124 (3) (2002) 238-253. doi:10.1016/s0032-5910(02)00020-7.

[30] J. Kumar, M. Peglow, G. Warnecke, S. Heinrich, An efficient numerical technique for solving population balance equation involving aggregation, breakage, growth and nucleation, Powder Technol. 182 (1) (2008) 81-104. doi:10.1016/j.powtec.2007.05.028.

[31] M. J. Hounslow, A Discretized Population Balance for Continuous Systems at Steady-State, AIChE J. 36 (1) (1990) 106-116. doi:10.1002/aic.690360113.

[32] S. Kumar, D. Ramkrishna, On the solution of population balance equations by discretization-I. A fixed pivot technique, Chem. Eng. Sci. 51 (8) (1996) 1311-1332. doi:10.1016/0009-2509(96)88489-2.

[33] S. Kumar, D. Ramkrishna, On the solution of population balance equations by discretization-II. A moving pivot technique, Chem. Eng. Sci. 51 (8) (1996) 1333-1342. doi:10.1016/0009-2509(95)00355-x.

[34] S. Kumar, D. Ramkrishna, On the solution of population balance equations by discretization-III. Nucleation, growth and aggregation of particles, Chem. Eng. Sci. 52 (24) (1997) 4659-4679. doi:10.1016/s0009-2509(97)00307-2.

[35] J. Li, L. Tao, M. Dali, D. Buckley, J. Gao, M. Hubert, The effect of the physical states of binders on high-shear wet granulation and granule properties: A mechanistic approach toward understanding high-shear wet granulation process. part ii. granulation and granule properties, J. Pharm. Sci. 100 (1) (2011) 294-310. doi:10.1002/jps.22261.

[36] C. L. Marshall, P. Rajniak, T. Matsoukas, Multi-component population balance modeling of granulation with continuous addition of binder, Powder Technol. 236 (2013) 211-220. doi:10.1016/j.powtec.2012.01.027.

[37] H. M. Vale, T. F. McKenna, Solution of the population balance equation for two-component aggregation by an extended fixed pivot technique, Ind. Eng. Chem. Res. 44 (20) (2005) 7885-7891. doi:10.1021/ie050179s.

[38] S. Qamar, G. Warnecke, Solving population balance equations for two-component aggregation by a finite volume scheme, Chem. Eng. Sci. 62 (3) (2007) 679-693. doi:10.1016/j.ces.2006.10.001. 
[39] A. Braumann, M. Kraft, Incorporating experimental uncertainties into multivariate granulation modelling, Chem. Eng. Sci. 65 (3) (2010) 1088-1100. doi:10.1016/j.ces.2009.09.063.

[40] A. Darelius, H. Brage, A. Rasmuson, I. N. Bjorn, S. Folestad, A volume-based multi-dimensional population balance approach for modelling high shear granulation, Chem. Eng. Sci. 61 (8) (2006) 2482-2493. doi:10.1016/j.ces.2005.11.016.

[41] C. D. Immanuel, F. J. Doyle, Solution technique for a multi-dimensional population balance model describing granulation processes, Powder Technol. 156 (2-3) (2005) 213-225. doi:10.1016/j.powtec.2005.04.013.

[42] C. A. Biggs, C. Sanders, A. C. Scott, A. W. Willemse, A. C. Hoffman, T. Instone, A. D. Salman, M. J. Hounslow, Coupling granule properties and granulation rates in high-shear granulation, Powder Technol. 130 (1-3) (2003) 162-168. doi:10.1016/S0032-5910(02)00260-7.

[43] D. Verkoeijen, G. A. Pouw, G. M. H. Meesters, B. Scarlett, Population balances for particulate processes - a volume approach, Chem. Eng. Sci. 57 (12) (2002) 2287-2303. doi:10.1016/s0009-2509(02)00118-5.

[44] R. Ramachandran, P. I. Barton, Effective parameter estimation within a multi-dimensional population balance model framework, Chem. Eng. Sci. 65 (16) (2010) 4884-4893. doi:10.1016/j.ces.2010.05.039.

[45] A. Darelius, A. Rasmuson, I. N. Björn, S. Folestad, High shear wet granulation modelling - a mechanistic approach using population balances, Powder Technol. 160 (3) (2005) 209-218. doi:10.1016/j.powtec.2005.08.036.

[46] R. Ramachandran, C. D. Immanuel, F. Stepanek, J. D. Litster, F. J. Doyle, A mechanistic model for breakage in population balances of granulation: Theoretical kernel development and experimental validation, Chem. Eng. Res. Des. 87 (4A) (2009) 598-614. doi:10.1016/j.cherd.2008.11.007.

[47] D. Barrasso, R. Ramachandran, A comparison of model order reduction techniques for a four-dimensional population balance model describing multi-component wet granulation processes, Chem. Eng. Sci. 80 (2012) 380-392. doi:10.1016/j.ces.2012.06.039.

[48] G. D. Ingram, I. T. Cameron, Dynamic Multiscale Modeling - An Application to Granulation Processes, in: Process Systems Engineering, Wiley-VCH Verlag GmbH \& Co. KGaA, 2010, pp. 35-65. doi:10.1002/9783527631339.ch2.

[49] P. C. Kapur, D. W. Fuerstenau, A Coalescence Model for Granulation, Ind Eng Chem, Process Des Dev 8 (1) (1969) 56-62. doi:10.1021/1260029a010.

[50] N. N. Rao, Simulations for modelling of population balance equations of particulate processes using the discrete particle model (DPM), Ph.D. thesis, Otto-von-Guericke-Universität Magdeburg, Universitätsbibliothek (2009).

[51] H. Wright, D. Ramkrishna, Solutions of inverse problems in population balances - I. Aggregation kinetics, Comput. Chem. Eng. 16 (12) (1992) 1019-1038. doi:10.1016/0098-1354(92)80021-Z.

[52] A. N. Sathyagal, D. Ramkrishna, G. Narsimhan, Solution of inverse problems in population balances-ii. particle break-up, Comput. Chem. Eng. 19 (4) (1995) 437-451. doi:10.1016/0098-1354(94)00062-S.

[53] A. Braumann, P. L. W. Man, M. Kraft, Statistical Approximation of the Inverse Problem in Multivariate Population Balance Modeling, Ind. Eng. Chem. Res. 49 (1) (2010) 428-438. doi:10.1021/ie901230u.

[54] M. Kostoglou, Chapter 18 The Linear Breakage Equation: From Fundamental Issues to Numerical Solution Techniques, in: M. G. Agba D. Salman, J. H. Michael (Eds.), Handbook of Powder Technology, Vol. Volume 12, Elsevier Science B.V., 2007, pp. 793-835. doi:10.1016/s0167-3785(07)12021-2.

[55] C. F. W. Sanders, A. W. Willemse, A. D. Salman, M. J. Hounslow, Development of a predictive high-shear granulation model, Powder Technol. 138 (1) (2003) 18-24. doi:10.1016/j.powtec.2003.08.046.

[56] G. K. Reynolds, J. S. Fu, Y. S. Cheong, M. Hounslow, A. D. Salman, Breakage in granulation: A review, Chem. Eng. Sci. 60 (14) (2005) 3969-3992. doi:10.1016/j.ces.2005.02.029.

[57] A. P. Dhanarajan, R. Bandyopadhyay, An energy-based population-balance approach to model granule growth and breakage in high-shear wet granulation processes., AAPS PharmSciTech 8 (3) (2007) E66. doi:10.1208/pt0803066.

[58] T. Abberger, Population balance modelling of granulation, in: M. J. H. A.D. Salman, J. P. K. Seville (Eds.), Hand- 
book of Powder Technology, Vol. Volume 11, Elsevier Science B.V., 2007, Ch. 24, pp. 1109-1186. doi:10.1016/S01673785(07)80059-5.

[59] J. Kumar, G. Warnecke, M. Peglow, S. Heinrich, Comparison of numerical methods for solving population balance equations incorporating aggregation and breakage, Powder Technol. 189 (2) (2009) 218-229. doi:10.1016/j.powtec.2008.04.014.

[60] C. L. Marshall, P. Rajniak, T. Matsoukas, Numerical simulations of two-component granulation: Comparison of three methods, Chem. Eng. Res. Des. 89 (5) (2011) 545-552. doi:10.1016/j.cherd.2010.06.003.

[61] D. L. Marchisio, R. D. Vigil, R. O. Fox, Quadrature method of moments for aggregation-breakage processes, J. Colloid Interface Sci. 258 (2) (2003) 322-334. doi:10.1016/s0021-9797(02)00054-1.

[62] D. L. Marchisio, R. O. Fox, Solution of population balance equations using the direct quadrature method of moments, J. Aerosol Sci. 36 (1) (2005) 43-73. doi:10.1016/j.jaerosci.2004.07.009.

[63] J. Gimbun, Z. K. Nagy, C. D. Rielly, Simultaneous quadrature method of moments for the solution of population balance equations, using a differential algebraic equation framework, Ind. Eng. Chem. Res. 48 (16) (2009) 7798-7812. doi:10.1021/Ie900548s.

[64] V. Kariwala, Y. Cao, Z. K. Nagy, Automatic differentiation-based quadrature method of moments for solving population balance equations, AIChE J. 58 (3) (2012) 842-854. doi:10.1002/Aic.12613.

[65] K. Lee, J. H. Lee, D. R. Yang, A. W. Mahoney, Integrated run-to-run and on-line model-based control of particle size distribution for a semi-batch precipitation reactor, Comput. Chem. Eng. 26 (7-8) (2002) 1117-1131. doi:10.1016/S00981354(02)00030-3.

[66] M. Smith, T. Matsoukas, Constant-number Monte Carlo simulation of population balances, Chem. Eng. Sci. 53 (9) (1998) 1777-1786. doi:10.1016/S0009-2509(98)00045-1.

[67] L. A. Spielman, O. Levenspiel, A Monte Carlo treatment for reacting and coalescing dispersed phase systems, Chem. Eng. Sci. 20 (3) (1965) 247-254. doi:10.1016/0009-2509(65)80035-5.

[68] J. Kumar, M. Peglow, G. Warnecke, S. Heinrich, L. Morl, Improved accuracy and convergence of discretized population balance for aggregation: The cell average technique, Chem. Eng. Sci. 61 (10) (2006) 3327-3342. doi:10.1016/j.ces.2005.12.014.

[69] C. D. Immanuel, F. J. Doyle, Computationally efficient solution of population balance models incorporating nucleation, growth and coagulation: application to emulsion polymerization, Chem. Eng. Sci. 58 (16) (2003) 3681-3698. doi:10.1016/S0009-2509(03)00216-1.

[70] B. Koren, A robust upwind discretization method for advection, diffusion and source terms, Centrum voor Wiskunde en Informatica Amsterdam, 1993.

[71] A. Kurganov, E. Tadmor, New high-resolution central schemes for nonlinear conservation laws and convection-diffusion equations, J. Comput. Phys. 160 (1) (2000) 241-282. doi:10.1006/jcph.2000.6459.

[72] A. Majumder, V. Kariwala, S. Ansumali, A. Rajendran, Lattice Boltzmann method for population balance equations with simultaneous growth, nucleation, aggregation and breakage, Chem. Eng. Sci. 69 (1) (2012) 316-328. doi:10.1016/j.ces.2011.10.051.

[73] A. Braumann, M. Kraft, P. R. Mort, Parameter estimation in a multidimensional granulation model, Powder Technol. 197 (3) (2010) 196-210. doi:10.1016/j.powtec.2009.09.014.

[74] J. Chakraborty, S. Kumar, A new framework for solution of multidimensional population balance equations, Chem. Eng. Sci. 62 (15) (2007) 4112-4125. doi:10.1016/j.ces.2007.04.049.

[75] M. N. Nandanwar, S. Kumar, A new discretization of space for the solution of multi-dimensional population balance equations, Chem. Eng. Sci. 63 (8) (2008) 2198-2210. doi:10.1016/j.ces.2008.01.015.

[76] R. Kumar, J. Kumar, G. Warnecke, Numerical methods for solving two-dimensional aggregation population balance equations, Comput. Chem. Eng. 35 (6) (2011) 999-1009. doi:10.1016/j.compchemeng.2010.08.002. 
[77] M. J. Hounslow, J. M. K. Pearson, T. Instone, Tracer studies of high-shear granulation: II. Population balance modeling, AIChE J. 47 (9) (2001) 1984-1999. doi:10.1002/aic.690470910.

[78] J. A. Gantt, I. T. Cameron, J. D. Litster, E. P. Gatzke, Determination of coalescence kernels for high-shear granulation using DEM simulations, Powder Technol. 170 (2) (2006) 53-63. doi:10.1016/j.powtec.2006.08.002.

[79] J. A. Gantt, E. P. Gatzke, High-shear granulation modeling using a discrete element simulation approach, Powder Technol. 156 (2-3) (2005) 195-212. doi:10.1016/j.powtec.2005.04.012.

[80] G. P. Lian, C. Thornton, M. J. Adams, Discrete particle simulation of agglomerate impact coalescence, Chem. Eng. Sci. 53 (19) (1998) 3381-3391. doi:10.1016/S0009-2509(98)00152-3.

[81] H. Nakamura, H. Fujii, S. Watano, Scale-up of high shear mixer-granulator based on discrete element analysis, Powder Technol. 236 (2013) 149-156. doi:10.1016/j.powtec.2012.03.009.

[82] W. R. Ketterhagen, M. T. am Ende, B. C. Hancock, Process modeling in the pharmaceutical industry using the discrete element method, J. Pharm. Sci. 98 (2) (2009) 442-470. doi:10.1002/jps.21466.

[83] H. Zhu, Z. Zhou, R. Yang, A. Yu, Discrete particle simulation of particulate systems: A review of major applications and findings, Chem. Eng. Sci. 63 (23) (2008) 5728-5770. doi:10.1016/j.ces.2008.08.006.

[84] H. J. Herrmann, S. Luding, Modeling granular media on the computer, Continuum Mech. Therm. 10 (4) (1998) $189-231$. doi: $10.1007 / \mathrm{s} 001610050089$.

[85] P. Y. Liu, R. Y. Yang, A. B. Yu, DEM study of the transverse mixing of wet particles in rotating drums, Chem. Eng. Sci. 86 (2013) 99-107. doi:10.1016/j.ces.2012.06.015.

[86] P. A. Cundall, O. D. L. Strack, A discrete numerical model for granular assemblies, Geotechnique 29 (1) (1979) $47-65$.

[87] P. W. Cleary, M. D. Sinnott, Assessing mixing characteristics of particle-mixing and granulation devices, Particuology 6 (6) (2008) 419-444. doi:10.1016/j.partic.2008.07.014.

[88] K. T. Lee, A. Ingram, N. A. Rowson, Twin screw wet granulation: the study of a continuous twin screw granulator using Positron Emission Particle Tracking (PEPT) technique., Eur. J. Pharm. Biopharm. 81 (3) (2012) 666-73. doi:10.1016/j.ejpb.2012.04.011.

[89] I. Talu, G. I. Tardos, M. I. Khan, Computer simulation of wet granulation, Powder Technol. 110 (1-2) (2000) 59-75. doi:10.1016/S0032-5910(99)00268-5.

[90] Y. Muguruma, T. Tanaka, Y. Tsuji, Numerical simulation of particulate flow with liquid bridge between particles (simulation of centrifugal tumbling granulator), Powder Technol. 109 (1-3) (2000) 49-57. doi:10.1016/S0032-5910(99)00226-0.

[91] B. K. Mishra, C. Thornton, D. Bhimji, A preliminary numerical investigation of agglomeration in a rotary drum, Miner. Eng. 15 (1-2) (2002) 27-33. doi:10.1016/S0892-6875(01)00194-7.

[92] M. J. V. Goldschmidt, Hydrodynamic modelling of fluidised bed spray granulation, Ph.D. thesis (2001).

[93] M. J. V. Goldschmidt, G. G. C. Weijers, R. Boerefijn, J. A. M. Kuipers, Discrete element modelling of fluidised bed spray granulation, Powder Technol. 138 (1) (2003) 39-45. doi:10.1016/j.powtec.2003.08.045.

[94] L. Fries, S. Antonyuk, S. Heinrich, D. Dopfer, S. Palzer, Collision dynamics in fluidised bed granulators: A DEM-CFD study, Chem. Eng. Sci. 86 (2013) 108-123. doi:10.1016/j.ces.2012.06.026.

[95] C. González-Montellano, A. Ramirez, E. Gallego, F. Ayuga, Validation and experimental calibration of 3D discrete element models for the simulation of the discharge flow in silos, Chem. Eng. Sci. 66 (21) (2011) 5116 - 5126. doi:http://dx.doi.org/10.1016/j.ces.2011.07.009.

[96] M. Marigo, M. Davies, T. Leadbeater, D. Cairns, A. Ingram, E. Stitt, Application of positron emission particle tracking (pept) to validate a discrete element method (dem) model of granular flow and mixing in the turbula mixer, International Journal of Pharmaceutics 446 (1-2) (2013) 46 - 58. doi:10.1016/j.ijpharm.2013.01.030.

[97] A. Braumann, M. J. Goodson, M. Kraft, P. R. Mort, Modelling and validation of granulation with heterogeneous binder dispersion and chemical reaction, Chem. Eng. Sci. 62 (17) (2007) 4717-4728. doi:10.1016/j.ces.2007.05.028. 
[98] B. Van Melkebeke, C. Vervaet, J. P. Remon, Validation of a continuous granulation process using a twin-screw extruder, Int. J. Pharm. 356 (1-2) (2008) 224-230. doi:10.1016/j.ijpharm.2008.01.012.

[99] G. Betz, P. J. Bürgin, H. Leuenberger, Power consumption profile analysis and tensile strength measurements during moist agglomeration, Int. J. Pharm. 252 (1-2) (2003) 11-25. doi:10.1016/S0378-5173(02)00601-4.

[100] T. De Beer, A. Burggraeve, M. Fonteyne, L. Saerens, J. P. Remon, C. Vervaet, Near infrared and Raman spectroscopy for the in-process monitoring of pharmaceutical production processes, Int. J. Pharm. 417 (1-2) (2011) 32-47. doi:10.1016/j.ijpharm.2010.12.012.

[101] S. Watano, Y. Sato, K. Miyanami, Application of a neural network to granulation scale-up, Powder Technol. 90 (2) (1997) 153-159. doi:10.1016/S0032-5910(96)03219-6.

[102] S. Watano, Direct control of wet granulation processes by image processing system, Powder Technol. 117 (1-2) (2001) 163-172. doi:10.1016/S0032-5910(01)00322-9.

[103] Y. Roggo, P. Chalus, L. Maurer, C. Lema-Martinez, A. A. Edmond, N. Jent, A review of near infrared spectroscopy and chemometrics in pharmaceutical technologies, J. Pharm. Biomed. Anal. 44 (3) (2007) 683-700. doi:10.1016/j.jpba.2007.03.023.

[104] E. M. Hansuld, L. Briens, A. Sayani, J. A. B. McCann, Monitoring quality attributes for high-shear wet granulation with audible acoustic emissions, Powder Technol. 215-216 (2012) 117-123. doi:10.1016/j.powtec.2011.09.034.

[105] J. Huang, G. Kaul, J. Utz, P. Hernandez, V. Wong, D. Bradley, A. Nagi, D. O'Grady, A PAT approach to improve process understanding of high shear wet granulation through in-line particle measurement using FBRM C35, J. Pharm. Sci. 99 (7) (2010) 3205-3212. doi:10.1002/jps.22089.

[106] E. Fukushima, Nuclear magnetic resonance as a tool to study flow, Annu. Rev. Fluid Mech. 31 (1) (1999) 95-123. doi:10.1146/annurev.fluid.31.1.95.

[107] A. Sakellariou, T. Sawkins, T. Senden, A. Limaye, X-ray tomography for mesoscale physics applications, Phys. Stat. Mech. Appl. 339 (1-2) (2004) 152-158. doi:10.1016/j.physa.2004.03.055.

[108] A. M. Nilpawar, G. K. Reynolds, A. D. Salman, M. J. Hounslow, Surface velocity measurement in a high shear mixer, Chem. Eng. Sci. 61 (13) (2006) 4172-4178. doi:10.1016/j.ces.2005.10.018.

[109] B. F. C. Laurent, Structure of powder flow in a planetary mixer during wet-mass granulation, Chem. Eng. Sci. 60 (14) (2005) 3805-3816. doi:10.1016/j.ces.2005.02.011.

[110] G. K. Reynolds, P. K. Le, A. M. Nilpawar, Chapter 1 High shear granulation, in: A.D. Salman, M J Hounslow and Seville, J P K (Ed.), Handbook of Powder Technology, Vol. 11, Elsevier Science B.V., 2007, Ch. 1, pp. 3-19. doi:10.1016/S01673785(07)80036-4.

[111] J. Vercruysse, U. Delaet, I. Van Assche, P. Cappuyns, F. Arata, G. Caporicci, T. De Beer, J. Remon, C. Vervaet, Stability and repeatability of a continuous twin screw granulation and drying system, Eur. J. Pharm. Biopharm.

[112] I. Ghebre-Selassie, C. Martin, Pharmaceutical extrusion technology, Vol. 133, CRC Press, 2003.

[113] K. Kohlgrüber, M. Bierdel, Co-rotating twin-screw extruders: fundamentals, technology, and applications, Hanser Verlag, 2008.

[114] R. M. Dhenge, J. J. Cartwright, M. J. Hounslow, A. D. Salman, Twin screw wet granulation: Effects of properties of granulation liquid, Powder Technol. 229 (2012) 126-136. doi:10.1016/j.powtec.2012.06.019.

[115] J. Vercruysse, D. Córdoba Díaz, E. Peeters, M. Fonteyne, U. Delaet, I. Van Assche, T. De Beer, J. P. Remon, C. Vervaet, Continuous twin screw granulation: influence of process variables on granule and tablet quality, Eur. J. Pharm. Biopharm. 82 (1) (2012) 205-211. doi:10.1016/j.ejpb.2012.05.010.

[116] D. Djuric, Continuous granulation with a twin-screw extruder, Cuvillier Verlag, 2008.

[117] M. R. Thompson, J. Sun, Wet granulation in a twin-screw extruder: Implications of screw design, J. Pharm. Sci. 99 (4) (2010) 2090-2103. doi:10.1002/jps.21973. 
[118] W.-D. Tu, A. Ingram, J. Seville, Regime map development for continuous twin screw granulation, Chem. Eng. Sci. 87 (2013) 315-326. doi:10.1016/j.ces.2012.08.015.

[119] K. T. Lee, A. Ingram, N. A. Rowson, Comparison of granule properties produced using Twin Screw Extruder and High Shear Mixer: A step towards understanding the mechanism of twin screw wet granulation, Powder Technol. 238 (2013) 91-98. doi:10.1016/j.powtec.2012.05.031.

[120] G. D. Ingram, I. T. Cameron, K. M. Hangos, Classification and analysis of integrating frameworks in multiscale modelling, Chem. Eng. Sci. 59 (11) (2004) 2171-2187.

[121] G. D. Ingram, I. T. Cameron, Formulation and comparison of alternative multiscale models for drum granulation, Comput. Aided Chem. Eng. 20 (2005) 481-486.

[122] Y. Gao, F. J. Muzzio, M. G. Ierapetritou, A review of the Residence Time Distribution (RTD) applications in solid unit operations, Powder Technol. 228 (2012) 416-423. doi:10.1016/j.powtec.2012.05.060.

[123] Y. Gao, A. Vanarase, F. Muzzio, M. Ierapetritou, Characterizing continuous powder mixing using residence time distribution, Chem. Eng. Sci. 66 (3) (2011) 417-425. doi:10.1016/j.ces.2010.10.045.

[124] A. Sarkar, C. R. Wassgren, Simulation of a continuous granular mixer: Effect of operating conditions on flow and mixing, Chem. Eng. Sci. 64 (11) (2009) 2672-2682. doi:10.1016/j.ces.2009.02.011.

[125] J. Bridgwater, Mixing of powders and granular materials by mechanical means - a perspective, Particuology.

[126] S. Watano, Chapter 10 Online monitoring, in: M. J. H. A.D. Salman, J. P. K. Seville (Eds.), Handbook of Powder Technology, Vol. Volume 11, Elsevier Science B.V., 2007, pp. 477-498. doi:10.1016/S0167-3785(07)80045-5.

[127] R. V. Chiruvella, Y. Jaluria, M. V. Karwe, V. Sernas, Transport in a twin-screw extruder for the processing of polymers, Polym. Eng. Sci. 36 (11) (1996) 1531-1540. doi:10.1002/pen.10548.

[128] D. Bigio, W. Stry, Measures of mixing in laminar flow, Polym. Eng. Sci. 30 (3) (1990) 153-161. doi:10.1002/pen.760300305.

[129] M. Barigou, Particle Tracking in Opaque Mixing Systems: An Overview of the Capabilities of PET and PEPT, Chem. Eng. Res. Des. 82 (9) (2004) 1258-1267. doi:10.1205/cerd.82.9.1258.44160.

[130] R. M. Dhenge, K. Washino, J. J. Cartwright, M. J. Hounslow, A. D. Salman, Twin screw granulation using conveying screws: Effects of viscosity of granulation liquids and flow of powders, Powder Technol. 238 (2013) 77-90. doi:10.1016/j.powtec.2012.05.045.

[131] Y. J. Choi, M. J. McCarthy, K. L. McCarthy, C. A. Davis, MRI for process analysis: co-rotating twin screw extruder, J. Process Anal. Chem 9 (2) (2004) 72-84.

[132] P. Kadlec, B. Gabrys, S. Strandt, Data-driven Soft Sensors in the process industry, Comput. Chem. Eng. 33 (4) (2009) 795-814. doi:10.1016/j.compchemeng.2008.12.012.

[133] K. V. Gernaey, R. Gani, A model-based systems approach to pharmaceutical product-process design and analysis, Chem. Eng. Sci. 65 (21) (2010) 5757-5769. doi:10.1016/j.ces.2010.05.003.

[134] J. A. Gantt, E. P. Gatzke, A stochastic technique for multidimensional granulation modeling, AIChE J. 52 (9) (2006) $3067-3077$

[135] M. Sen, A. Dubey, R. Singh, R. Ramachandran, Mathematical development and comparison of a hybrid PBM-DEM description of a continuous powder mixing process, J. Powder Technol. 2013.

[136] F. Štěpánek, P. Rajniak, C. Mancinelli, R. Chern, R. Ramachandran, Distribution and accessibility of binder in wet granules, Powder Technol. 189 (2) (2009) 376-384.

[137] P. Rajniak, F. Stepanek, K. Dhanasekharan, R. Fan, C. Mancinelli, R. Chern, A combined experimental and computational study of wet granulation in a wurster fluid bed granulator, Powder Technol. 189 (2) (2009) $190-201$.

[138] T. R. Camp, P. C. Stein, Velocity gradients and internal work in fluid motion, J. Boston Soc. Civ. Eng. 85 (1943) $219-237$.

[139] P. C. Kapur, Kinetics of granulation by non-random coalescence mechanism, Chem. Eng. Sci. 27 (10) (1972) $1863-1869$. doi:10.1016/0009-2509(72)85048-6. 
[140] K. V. S. Sastry, Similarity size distribution of agglomerates during their growth by coalescence in granulation or green pelletization, Int. J. Miner. Process. 2 (2) (1975) 187-203. doi:10.1016/0301-7516(75)90021-6.

[141] A. A. Adetayo, J. D. Litster, S. E. Pratsinis, B. J. Ennis, Population Balance Modeling of Drum Granulation of Materials with Wide Size Distribution, Powder Technol. 82 (1) (1995) 37-49. doi:10.1016/0032-5910(94)02896-V.

[142] A. A. Adetayo, B. J. Ennis, Unifying approach to modeling granule coalescence mechanisms, AIChE J. 43 (4) (1997) 927-934. doi:10.1002/aic.690430408.

[143] M. J. Hounslow, The population balance as a tool for understanding particle rate processes, Kona 16 (1998) $179-193$.

[144] S. A. Cryer, Modeling agglomeration processes in fluid-bed granulation, AIChE J. 45 (10) (1999) $2069-2078$. doi:10.1002/aic.690451005.

[145] Y. Liu, I. T. Cameron, A new wavelet-based method for the solution of the population balance equation, Chem. Eng. Sci. 56 (18) (2001) 5283-5294. doi:10.1016/S0009-2509(01)00196-8.

[146] L. Madec, L. Falk, E. Plasari, Modelling of the agglomeration in suspension process with multidimensional kernels, Powder Technol. 130 (1-3) (2003) 147-153. doi:10.1016/S0032-5910(02)00258-9.

[147] J. D. Pandya, L. A. Spielman, Floc Breakage in Agitated Suspensions - Effect of Agitation Rate, Chem. Eng. Sci. 38 (12) (1983) 1983-1992. doi:10.1016/0009-2509(83)80102-X.

[148] R. B. Diemer, J. H. Olson, A moment methodology for coagulation and breakage problems: Part 2 moment models and distribution reconstruction, Chem. Eng. Sci. 57 (12) (2002) 2211-2228. doi:10.1016/s0009-2509(02)00112-4.

[149] P. J. Hill, K. M. Ng, New discretization procedure for the breakage equation, AIChE J. 41 (5) (1995) $1204-1216$. doi:10.1002/aic.690410516.

[150] M. Kostoglou, A. J. Karabelas, On the breakage problem with a homogeneous erosion type kernel, Phys. A 34 (8) (2001) 1725-1740. doi:10.1088/0305-4470/34/8/316.

[151] M. Kostoglou, A. J. Karabelas, Theoretical analysis of the steady state particle size distribution in limited breakage processes, Phys. A 31 (44) (1998) 8905-8921. doi:10.1088/0305-4470/31/44/015.

[152] M. Kostoglou, Exact self-similar solutions to the fragmentation equation with homogeneous discrete kernel, Phys. A 320 (2003) 84-96. doi:10.1016/S0378-4371(02)01537-6.

[153] A. Sato, E. Serris, P. Grosseau, G. Thomas, L. Galet, A. Chamayou, M. Baron, Experiment and simulation of dry particle coating, Chemical Engineering Science 86 (2013) 164 - 172, 5th International Granulation Workshop. doi:10.1016/j.ces.2012.07.037.

[154] F. Thielmann, M. Naderi, M. A. Ansari, F. Stepanek, The effect of primary particle surface energy on agglomeration rate in fluidised bed wet granulation, Powder Technology 181 (2) (2008) 160 - 168, particulate Processes in the Pharmaceutical Industry. doi:http://dx.doi.org/10.1016/j.powtec.2006.12.015.

[155] P. Luukkonen, J. Newton, F. Podczeck, J. Yliruusi, Use of a capillary rheometer to evaluate the rheological properties of microcrystalline cellulose and silicified microcrystalline cellulose wet masses, Int. J. Pharm. 216 (1-2) (2001) $147-157$. doi:10.1016/S0378-5173(01)00585-3.

[156] J. M.-H. Poon, R. Ramachandran, C. F. Sanders, T. Glaser, C. D. Immanuel, F. J. D. III, J. D. Litster, F. Stepanek, F.-Y. Wang, I. T. Cameron, Experimental validation studies on a multi-dimensional and multi-scale population balance model of batch granulation, Chemical Engineering Science 64 (4) (2009) 775 - 786, 3rd International Conference on Population Balance Modelling. doi:10.1016/j.ces.2008.08.037.

[157] N. Sandler, D. Wilson, Prediction of granule packing and flow behavior based on particle size and shape analysis, J. Pharm. Sci. 99 (2) (2010) 958-968. doi:10.1002/jps.21884.

[158] R. Moreno-Atanasio, S. Antony, M. Ghadiri, Analysis of flowability of cohesive powders using distinct element method, Powder Technology 158 (1-3) (2005) 51 - 57. doi:10.1016/j.powtec.2005.04.029.

[159] Z. A. Arp, C. Mcdade, Temperature telemetry in processing of material, US Patent No. 2010/0203227 (Aug 2010). 
[160] E. L. Chan, G. K. Reynolds, B. Gururajan, M. J. Hounslow, A. D. Salman, Blade granule bed stress in a cylindrical high shear granulator: Online measurement and characterisation, Chem. Eng. Sci. 86 (2013) 38-49. doi:10.1016/j.ces.2012.04.019.

[161] S. M. Lee, J. C. Park, Y. J. Ahn, J. W. Lee, In-line measurement of residence time distribution in twin-screw extruder using non-destructive ultrasound, Korea-Aust. Rheol. J. 17 (2) (2005) 87-95.

[162] G. Horsthuis, J. Vanlaarhoven, R. Vanrooij, H. Vromans, Studies on upscaling parameters of the Gral high shear granulation process, Int. J. Pharm. 92 (1-3) (1993) 143-150. doi:10.1016/0378-5173(93)90273-I.

[163] Y. Sato, H. Nakamura, S. Watano, Numerical analysis of agitation torque and particle motion in a high shear mixer, Powder Technol. 186 (2) (2008) 130 - 136. doi:10.1016/j.powtec.2007.11.028.

[164] W. F. Sakr, M. A. Ibrahim, F. K. Alanazi, A. A. Sakr, Upgrading wet granulation monitoring from hand squeeze test to mixing torque rheometry, Saudi Pharm. J. 20 (1) (2012) 9-19. doi:10.1016/j.jsps.2011.04.007.

[165] A. Faure, I. M. Grimsey, R. C. Rowe, P. York, M. J. Cliff, Process control in a high shear mixer- granulator using wet mass consistency: The effect of formulation variables, J. Pharm. Sci. 88 (2) (1999) 191-195.

[166] S. Watano, E. Numa, K. Miyanami, Y. Osako, On-line monitoring of granule growth in high shear granulation by an image processing system, Chem. Pharm. Bull. (Tokyo) 48 (8) (2000) 1154.

[167] S. Antonyuk, M. Khanal, J. Tomas, S. Heinrich, L. Mörl, Impact breakage of spherical granules: Experimental study and DEM simulation, Chem. Eng. Process. 45 (10) (2006) 838 - 856, Particulate Processes A Special Issue of Chemical Engineering and Processing. doi:10.1016/j.cep.2005.12.005.

[168] J. Rantanen, H. k. Wikström, R. Turner, L. S. Taylor, Use of In-Line Near-Infrared Spectroscopy in Combination with Chemometrics for Improved Understanding of Pharmaceutical Processes, Anal. Chem. 77 (2) (2004) 556-563. doi:10.1021/ac048842u.

[169] J. N. Michaels, L. Farber, G. S. Wong, K. Hapgood, S. J. Heidel, J. Farabaugh, J. H. Chou, G. I. Tardos, Steady states in granulation of pharmaceutical powders with application to scale-up, Powder Technol. 189 (2) (2009) 295-303. doi:10.1016/j.powtec.2008.04.028.

[170] M. Whitaker, G. R. Baker, J. Westrup, P. A. Goulding, D. R. Rudd, R. M. Belchamber, M. P. Collins, Application of acoustic emission to the monitoring and end point determination of a high shear granulation process, Int. J. Pharm. 205 (1-2) (2000) 79-91. doi:10.1016/S0378-5173(00)00479-8.

[171] M. Fonteyne, S. Soares, J. Vercruysse, E. Peeters, A. Burggraeve, C. Vervaet, J. P. Remon, N. Sandler, T. De Beer, Prediction of quality attributes of continuously produced granules using complementary pat tools, Eur. J. Pharm. Biopharm. 82 (2) (2012) 429-436. doi:10.1016/j.ejpb.2012.07.017.

[172] P. A. Tishmack, D. E. Bugay, S. R. Byrn, Solid-state nuclear magnetic resonance spectroscopy-pharmaceutical applications., J. Pharm. Sci. 92 (3) (2003) 441-74. doi:10.1002/jps.10307.

[173] V. Rimpiläinen, S. Poutiainen, L. M. Heikkinen, T. Savolainen, M. Vauhkonen, J. Ketolainen, Electrical capacitance tomography as a monitoring tool for high-shear mixing and granulation, Chem. Eng. Sci. 66 (18) (2011) 4090-4100.

[174] M. Sen, R. Singh, A. Vanarase, J. John, R. Ramachandran, Multi-dimensional population balance modeling and experimental validation of continuous powder mixing processes, Chemical Engineering Science 80 (2012) 349 - 360. doi:http://dx.doi.org/10.1016/j.ces.2012.06.024.

[175] A. Hassanpour, M. Pasha, L. Susana, N. Rahmanian, A. C. Santomaso, M. Ghadiri, Analysis of seeded granulation in high shear granulators by discrete element method, Powder Technol. 238 (2013) 50 - 55, Special Issue: 5th International Granulation Workshop Granulation across the length scale 2011. doi:10.1016/j.powtec.2012.06.028.

[176] Z. Guo, M. Ma, T. Wang, D. Chang, T. Jiang, S. Wang, A Kinetic Study of the Polymorphic Transformation of Nimodipine and Indomethacin during High Shear Granulation, AAPS PharmSciTech 12 (2) (2011) 610-619.

[177] A. C. Jørgensen, et al., Increasing process understanding of wet granulation by spectroscopic methods and dimension 
reduction tools, University of Helsinki, 2004

[178] C. W. Propst, Granulation Characterization, 3rd Edition, 2009, Ch. 22, pp. 469-486. doi:10.3109/9781616310035.022. 
Table 1: Benefits and challenges of continuous processing

\begin{tabular}{|l|l|}
\hline \multicolumn{1}{|c|}{ Benefits } & \multicolumn{1}{c|}{ Challenges } \\
\hline Improved and more consistent quality & More precise measurement and control required \\
Increased throughput & Continuous flow and level measurement \\
Reduced inventory and associated storage & Modulating flow and level control \\
Reduced raw material usage & Real-time in-process quality measurement \\
Reduced waste products & Real-time quality control \\
Improved process safety & Integration of several unit operations, also w.r.t. \\
& control \\
Reduced air, water and power utility usage & Extensive personnel training, particularly for op- \\
& erators \\
Reduced process footprint & Redundant controls and instrumentation \\
Reduced clean-up time & Rapid corrections to all process variations \\
Reduced operator involvement & Advanced process control \\
\hline
\end{tabular}

Table 2: Various granulation processes used in the pharmaceutical industries

\begin{tabular}{|c|l|l|}
\hline Method & \multicolumn{2}{|c|}{ Process } \\
\hline \multirow{3}{*}{ Dry granulation } & & $\begin{array}{l}\text { Direct compression } \\
\text { Slugging (double compression) } \\
\text { Roller compaction }\end{array}$ \\
\hline \multirow{3}{*}{ Wet granulation } & \multirow{2}{*}{ Low shear techniques } & $\begin{array}{l}\text { Low shear mixer } \\
\text { Fluid-bed granulator dryer } \\
\text { Continuous fluid-bed granulator/dryer }\end{array}$ \\
\cline { 2 - 3 } & \multirow{2}{*}{ High shear techniques } & $\begin{array}{l}\text { Low shear mixer } \\
\text { Fluid-bed granulator dryer } \\
\text { Continuous fluid-bed granulator/dryer }\end{array}$ \\
\hline
\end{tabular}

Table 3: Comparison of high-shear wet granulation to other granulation techniques

\begin{tabular}{|c|c|c|}
\hline Granulation Parameter & $\begin{array}{l}\text { High-shear wet } \\
\text { granulation }\end{array}$ & $\begin{array}{l}\text { Other granulation } \\
\text { methods }\end{array}$ \\
\hline Processing time & Short & Long \\
\hline Operating conditions & Narrow range & Wide range \\
\hline Use of granulation liquid & Less & More \\
\hline $\begin{array}{l}\text { For highly cohesive materials contain- } \\
\text { ing hydrophilic powder }\end{array}$ & Achievable & Not achievable \\
\hline Densification of granules & Greater & Lower \\
\hline Friability of granules & Less & More \\
\hline $\begin{array}{l}\text { Process reproducibility w.r.t. uni- } \\
\text { form GSD }\end{array}$ & More & Less \\
\hline Reduction of process dust & More & Less \\
\hline Granulation end point determination & Predictable & Poor predictability \\
\hline Granule compressibility & Less & More \\
\hline Hardness & More & Less \\
\hline
\end{tabular}




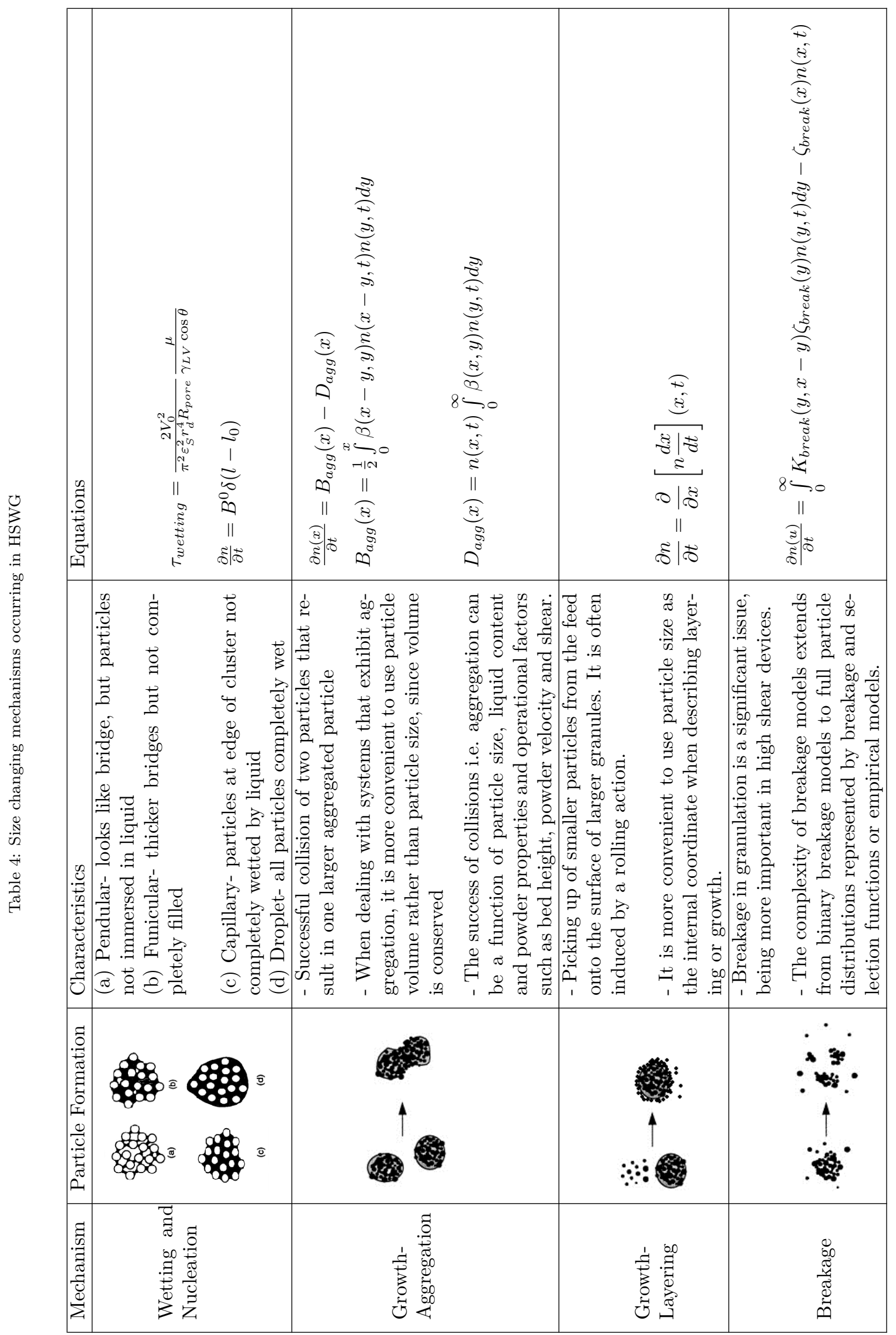


Table 5: Physical modeling approaches in granulation studies

\begin{tabular}{|l|l|l|l|}
\hline \multicolumn{1}{|c|}{ Model } & \multicolumn{1}{|c|}{ Advantages } & \multicolumn{1}{c|}{ Challenges } \\
\hline $\begin{array}{l}\text { 1. Population bal- } \\
\text { (PBM) modelling }\end{array}$ & $\begin{array}{l}\text { Simulate a very large } \\
\text { number of particles }\end{array}$ & $\begin{array}{l}\text { Semi-mechanistic approach due } \\
\text { to lack of process knowledge }\end{array}$ & $\begin{array}{l}{[40,} \\
45-47]\end{array}$ \\
\hline $\begin{array}{l}\text { 2. Discrete element } \\
\text { method (DEM) }\end{array}$ & $\begin{array}{l}\text { Mechanistic approach } \\
\text { Computational limitations when } \\
\text { very large number of particles }\end{array}$ & {$[81]$} \\
\hline $\begin{array}{l}\text { by combining PBM } \\
\text { with DEM }\end{array}$ & $\begin{array}{l}\text { Capable of modelling the } \\
\text { nisms by bridging micro- } \\
\text { scale to meso-scale }\end{array}$ & $\begin{array}{l}\text { Hard to implement due to many } \\
\text { many difficulties, for example to } \\
\text { granule yield strength, asperity } \\
\text { height etc. }\end{array}$ & {$[134$,} \\
\hline $\begin{array}{l}\text { 4. PBM with Vol- } \\
\text { ume of Fluid (VoF) } \\
\text { methods }\end{array}$ & $\begin{array}{l}\text { Mechanistic approach; } \\
\text { Can provide spatial dis- } \\
\text { tribution of binder in wet } \\
\text { granule }\end{array}$ & $\begin{array}{l}\text { Hard to implement and requires } \\
\text { considerable simplification such } \\
\text { as ignoring dynamic change in } \\
\text { state of granulation liquid }\end{array}$ & {$[136]$} \\
\hline $\begin{array}{l}\text { 5. PBM with Com- } \\
\text { putational fluid dy- } \\
\text { namics (CFD) }\end{array}$ & $\begin{array}{l}\text { Mechanistic approach; can } \\
\text { be used for development of } \\
\text { simplified models }\end{array}$ & $\begin{array}{l}\text { Not suitable for dense particle } \\
\text { system; ignores particle-particle } \\
\text { interaction }\end{array}$ & {$[137]$} \\
\hline $\begin{array}{l}\text { 6. PBM with Com- } \\
\text { partmental model } \\
\text { (CM) and DEM }\end{array}$ & $\begin{array}{l}\text { Improved accuracy of the } \\
\text { population balance model } \\
\text { when the particle flow is } \\
\text { an important parameter }\end{array}$ & $\begin{array}{l}\text { Number of particles is low while } \\
\text { stochastic solution methods of } \\
\text { PBM are adopted to avoid com- } \\
\text { putational limitations }\end{array}$ & {$[28]$} \\
\hline
\end{tabular}


Table 6: Summary of chronological evolution of different collision frequency functions for aggregation kernels in the literature

\begin{tabular}{|c|c|}
\hline Kernels & Source \\
\hline $\begin{array}{l}\text { Shear kernel } \\
\beta=\beta_{0} \cdot \frac{4}{3} G\left(a_{i}+a_{j}\right)^{3} \\
\text { where } G \text { is the local velocity gradient. }\end{array}$ & [138] \\
\hline $\begin{array}{l}\text { Size independent kernel } \\
\beta=\beta_{0}\end{array}$ & [48] \\
\hline $\begin{array}{l}\text { Size dependent kernel } \\
\beta=\beta_{0} \frac{\left(x+x^{\prime}\right)^{a}}{\left(x \cdot x^{\prime}\right)^{b}}\end{array}$ & [139] \\
\hline $\begin{array}{l}\text { Time and size dependent kernel } \\
\beta=\beta_{0}(t) \cdot \beta^{*}\left(x, x^{\prime}\right) \\
\text { where one is a time-dependent and the other a size-dependent function }\end{array}$ & [140] \\
\hline $\begin{array}{l}\text { Sequential kernel } \\
\beta= \begin{cases}\beta_{0}, & \mathrm{t}<\mathrm{t}_{\text {switch }} \\
\beta_{1}\left(x, x^{\prime}\right), & \mathrm{t}>\mathrm{t}_{\mathrm{switch}}\end{cases} \\
\text { where } \beta_{0} \text { and } \beta_{1} \text { are constants and } t_{\text {switch }} \text { is the time required to reach the final } \\
\text { equilibrium size distribution of the first non-inertial stage of granulation. }\end{array}$ & {$[141]$} \\
\hline $\begin{array}{l}\text { Cut-off kernel } \\
\beta=\left\{\begin{array}{l}\beta_{0}, w<w * \\
0, w>w *\end{array} \text { where } w=\frac{\left(x \cdot x^{\prime}\right)^{a} A E}{\left(x+x^{\prime}\right)^{b} A E}\right. \\
a_{A E}, b_{A E}, \beta_{0} \text { are constants and } w * \text { is the critical granule volume. }\end{array}$ & {$[142]$} \\
\hline $\begin{array}{l}\text { EKE kernel (Equipartition of Kinetic Energy-kernel) } \\
\beta=\beta_{0}\left(x+x^{\prime}\right)^{2} \sqrt{\frac{1}{x^{3}}+\frac{1}{x^{\prime 3}}}\end{array}$ & {$[143]$} \\
\hline $\begin{array}{l}\text { ETM kernel (Equipartition of Translational Momentum kernel) } \\
\beta=\beta_{0}\left(x+x^{\prime}\right)^{2} \sqrt{\frac{1}{x^{6}}+\frac{1}{x^{\prime 6}}}\end{array}$ & [143] \\
\hline $\begin{array}{l}\text { physically based kernel } \\
\beta=\beta_{0} \int_{-\infty}^{S t *} f(\Phi, t) d \Phi \\
\text { where, } f(\Phi, t) \text { is the discrete probability density function. }\end{array}$ & {$[144]$} \\
\hline $\begin{array}{l}\text { Kernel based on the different aggregation mechanisms } \\
\left.\beta\right|_{x, x^{\prime}}=\left\{\begin{array}{l}\beta_{1}: \text { for type I and type II coalescence with no permanent deformation } \\
\beta_{2}: \text { for type II coalescence with permanent deformation } \\
0: \text { for rebound }\end{array}\right.\end{array}$ & {$[145]$} \\
\hline $\begin{array}{l}\text { Multidimensional kernel } \\
\beta=\beta_{0} \cdot\left(x^{3}+x^{3}\right)\left(\left(c_{x}+c_{x^{\prime}}\right)^{\alpha_{M}}\left(100-\frac{c_{x}+c_{x^{\prime}}}{2}\right)^{\delta_{M}}\right)^{\alpha_{M}} \\
\text { where } c_{x} \text { and } c_{x^{\prime}} \text { represent the volume percentage of binding agent in the agglomerates } \\
x \text { and } x^{\prime} \text { respectively, and } \alpha_{M} \text { and } \delta_{M} \text { are fitted parameters. }\end{array}$ & [146] \\
\hline $\begin{array}{l}\text { Mechanistic kernel } \\
\beta(i, j, t)=\beta_{0} \frac{q_{l i}-q_{l^{*} i}}{4 \pi\left(\left(d_{i} / 2\right)\right)^{2}\left(\left(q_{s i}+q_{l i}\right) / v_{i}\right)}-\frac{q_{l j}-q_{l^{*} j}}{4 \pi\left(\left(d_{j} / 2\right)\right)^{2}\left(\left(q_{s j}+q_{l j}\right) / v_{j}\right)} \\
\text { where, } q_{l i} \text { is the volume of liquid in class } i, q_{l *} ; \text { the volume of liquid in the voids in } \\
\text { class } i, \text { and } v_{i} \text { refers to the volume of a single particle in class } i \text {. }\end{array}$ & [40] \\
\hline
\end{tabular}


Table 7: Summary of chronological evolution of breakage kernels in the literature

\begin{tabular}{|c|c|}
\hline Kernels & Source \\
\hline $\begin{array}{l}\text { Semi-empirical breakage kernel } \\
K_{\text {break }}(z)=\frac{P_{1} G_{\text {shear }}(D(z))^{P_{2}}}{2} \\
\text { where } G \text { is the shear rate, } D \text { is the particle diameter, and } P_{1} \text { and } P_{2} \text { are } \\
\text { adjustable parameters. }\end{array}$ & [147] \\
\hline $\begin{array}{l}\text { Product and sum-type : } \\
K_{\text {break }}(z)=v \frac{z^{q-1}(1-z)^{q(v-1)-1}}{B(q, q(v-1))} \\
K_{\text {break }}(z)=\frac{z^{q-1}(1-z)^{v-2}}{B(q, v-1)}+(v-1) \frac{(1-z)^{q+v-3}}{B(1, q+v-2))} \\
\text { where } B \text { is the beta function, } v(y)=v(\geq 2) \text { is the number of fragments per } \\
\text { breakage event and } q>0 \text { is the parameter of the kernel. }\end{array}$ & {$[148,149]$} \\
\hline $\begin{array}{l}\text { Erosion-type kernels: } \\
K_{\text {break }}(z)=\left\{\begin{array}{ll}P_{1}(z) & \text { for } 0<z<\varepsilon_{1} \\
0 & \text { for } \varepsilon_{1}<\mathrm{z}<\varepsilon_{2} \\
P_{2}(z) & \text { for } 1-\varepsilon_{2}<\mathrm{z}<1\end{array} \text { with } \varepsilon_{2}<<1\right.\end{array}$ & [150] \\
\hline $\begin{array}{l}\text { Sum of the powers-type kernel: } \\
K_{\text {break }}(z)=\sum_{i=1}^{n} c_{i} z^{k_{i}} \\
\text { where } k_{i} \in(-2, \infty) \text {. The coefficients } c_{i} \text { must be such as to conserve the total } \\
\text { mass, that is } \sum_{i=1}^{n} \frac{c_{i}}{k_{i}+2}=1\end{array}$ & [151] \\
\hline $\begin{array}{l}\text { Discrete homogeneous kernels } \\
K_{\text {break }}(z)=\sum_{i=1}^{n} a_{i} \delta\left(z-c_{i}\right)\end{array}$ & [152] \\
\hline $\begin{array}{l}\text { Mechanistic breakage kernel } \\
K_{\text {break }}\left(z_{a}\right)=\sum_{z_{a}=1}^{z_{a_{\text {upper }}}} \frac{\sigma_{\text {ext }}^{\text {particle }}\left(z_{a}, z_{b}\right)}{\sigma_{\text {int }}\left(z_{a}\right)} F\left(z_{a}\right) N_{a} \frac{S A\left(z_{a}\right)}{S A+W A+I A}+\frac{\sigma_{e x t}^{\text {wall }}\left(z_{a}\right)}{\sigma_{\text {int }}\left(z_{a}\right)} \frac{W A}{S A+W A+I A}+ \\
\frac{\sigma_{\text {ext }}^{\text {impeller }}\left(z_{a}\right)}{\sigma_{\text {int }}\left(z_{a}\right)} \frac{I A}{S A+W A+I A}+\frac{\sigma_{\text {ext }}^{\text {fluid }}\left(z_{a}\right)}{\sigma_{\text {int }}\left(z_{a}\right)} \\
\text { where } F \text { is the particle density, } W A \text { is the total wall surface area, } S A \text { is the } \\
\text { surface area of an individual particle, } I A \text { is the impeller surface area and } N_{a} \text { is } \\
\text { Avogadro's constant, } z_{a_{u p p e r}} \text { are the upper limits of the finite volumes in each } \\
\text { of the dimensions. }\end{array}$ & {$[46]$} \\
\hline
\end{tabular}


Table 8: Advantages and drawbacks of various DEM schemes

\begin{tabular}{|c|c|}
\hline Hard-sphere models & Soft-sphere models \\
\hline $\begin{array}{l}\text { Advantages: } \\
\text { 1. High accuracy in the particle dynamics as } \\
\text { the Newtonian equations of motion for each } \\
\text { individual particle are solved with inclusion } \\
\text { of the effects of contact forces acting on the } \\
\text { particles and gravitation. } \\
\text { 2. Larger number of particles can be included } \\
\text { into the hard-sphere models compared to soft- } \\
\text { sphere models. }\end{array}$ & $\begin{array}{l}\text { 1. Promising tool for studying the effect at } \\
\text { particle level of changes in some of the physical } \\
\text { parameters involved in the granulation pro- } \\
\text { cess. } \\
\text { 2. Theoretical particle level models may be } \\
\text { validated using the soft-sphere approach as } \\
\text { numerous variations in the physical/chemical } \\
\text { parameters may be simulated relatively fast } \\
\text { once the simulation program is set up. } \\
\text { 3. Well suited for studying the modelling of } \\
\text { impact breakage of pre-existing agglomerates } \\
\text { which is important in high shear granulation } \\
\text { systems. }\end{array}$ \\
\hline $\begin{array}{l}\text { Drawbacks: } \\
\text { 1. Generally not suitable for realistic represen- } \\
\text { tation of the granule micro-structure (i.e. the } \\
\text { internal distribution of primary solids, granu- } \\
\text { lation liquid and porosity of the granule). } \\
\text { 2. Present models are only capable of account- } \\
\text { ing for } 1 \text { million particles at a time, thereby } \\
\text { making simulations comparable only to exper- } \\
\text { imental data from laboratory scale equipment. }\end{array}$ & $\begin{array}{l}\text { 2. Detailed information of binary collisions is } \\
\text { far from being representative of the situation } \\
\text { inside a dense particle high shear system and } \\
\text { requires more research. }\end{array}$ \\
\hline
\end{tabular}




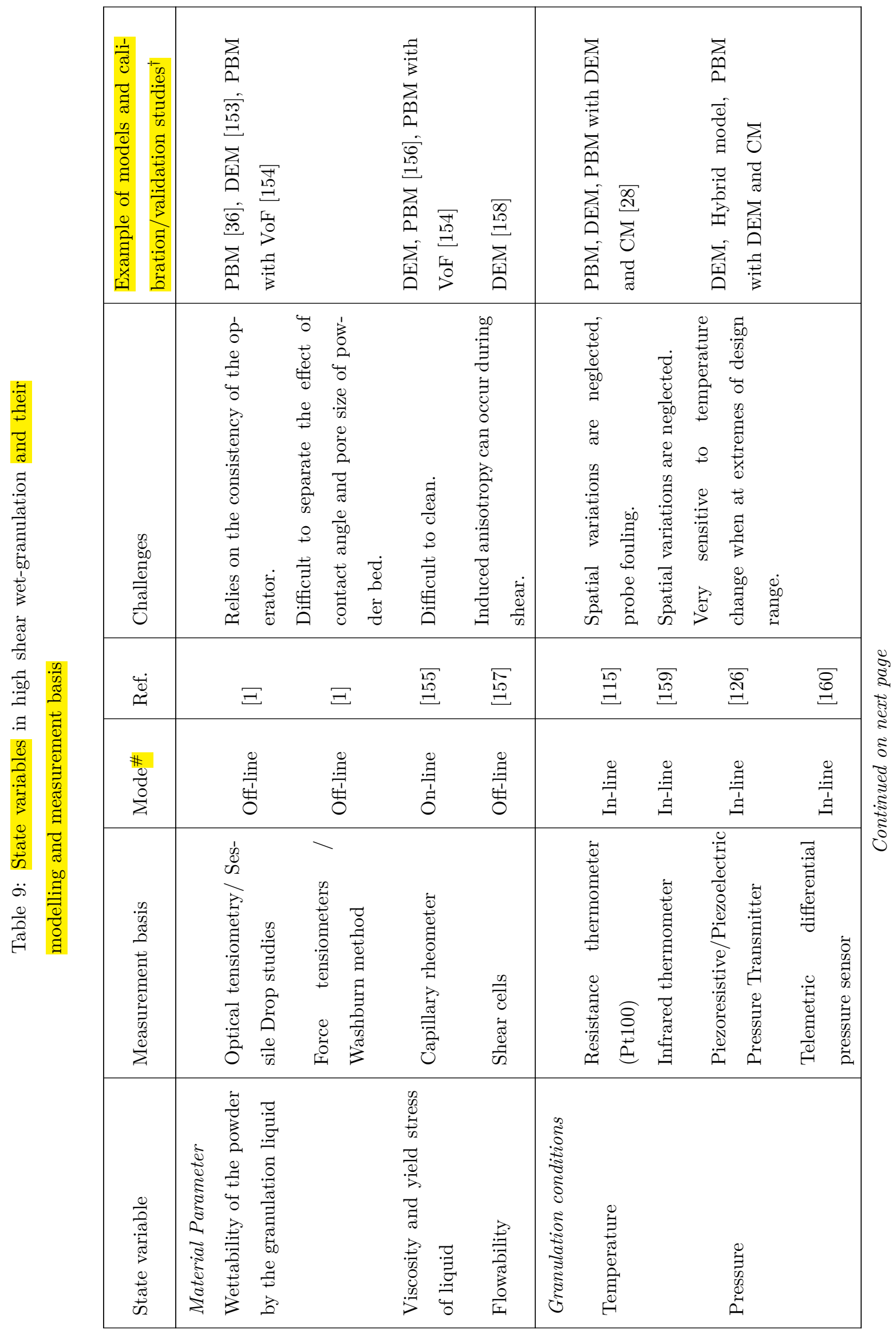




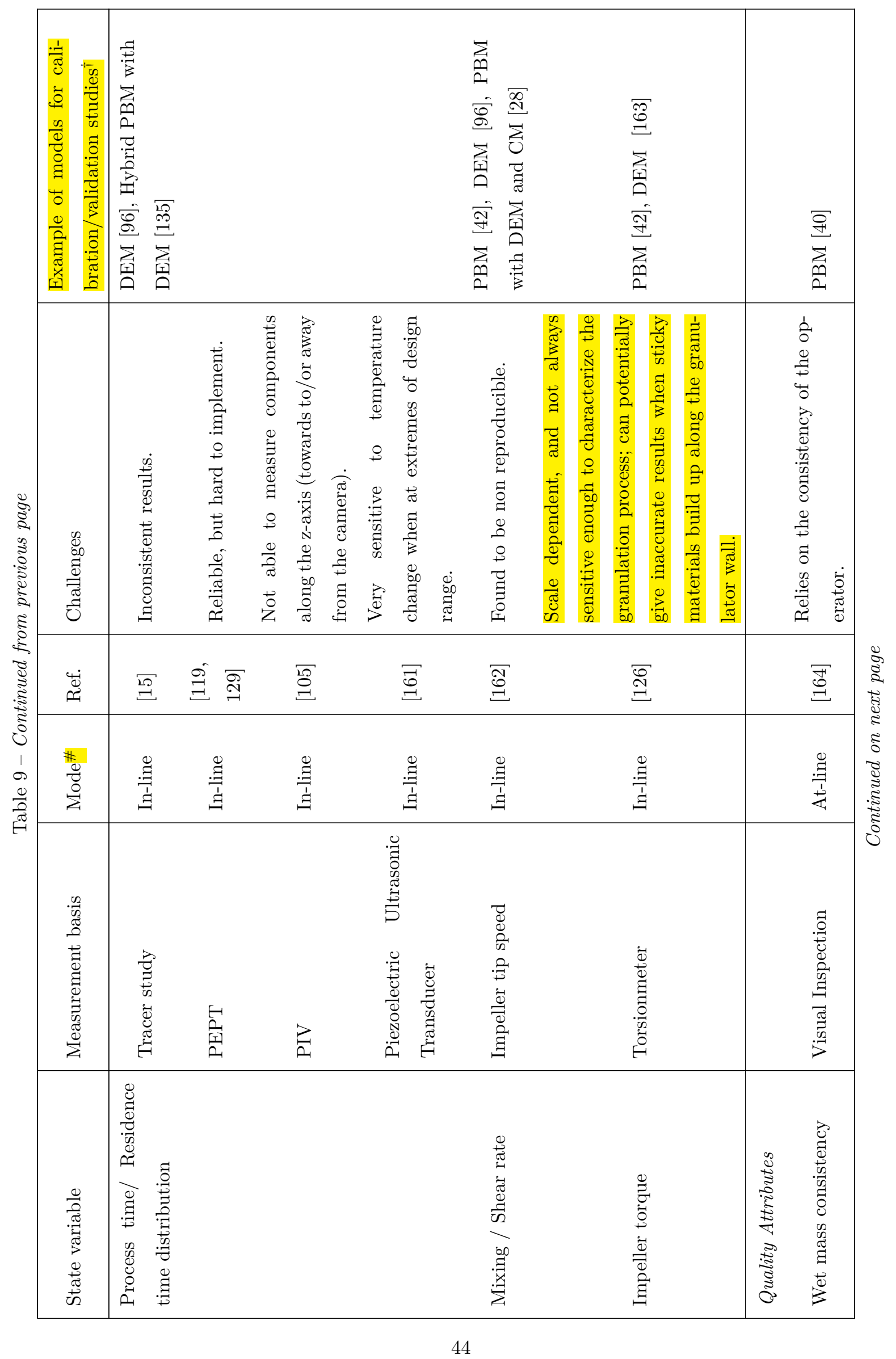




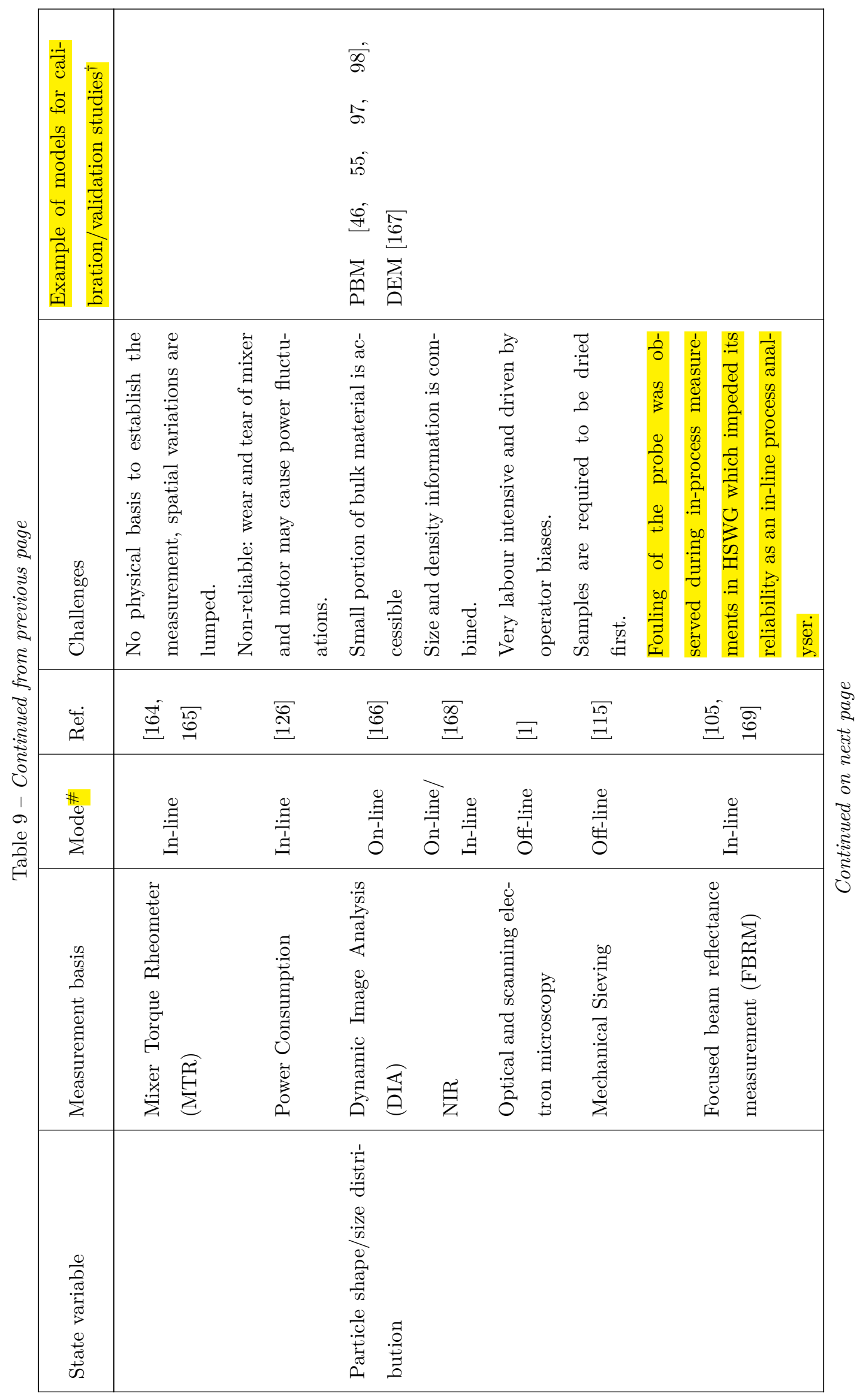




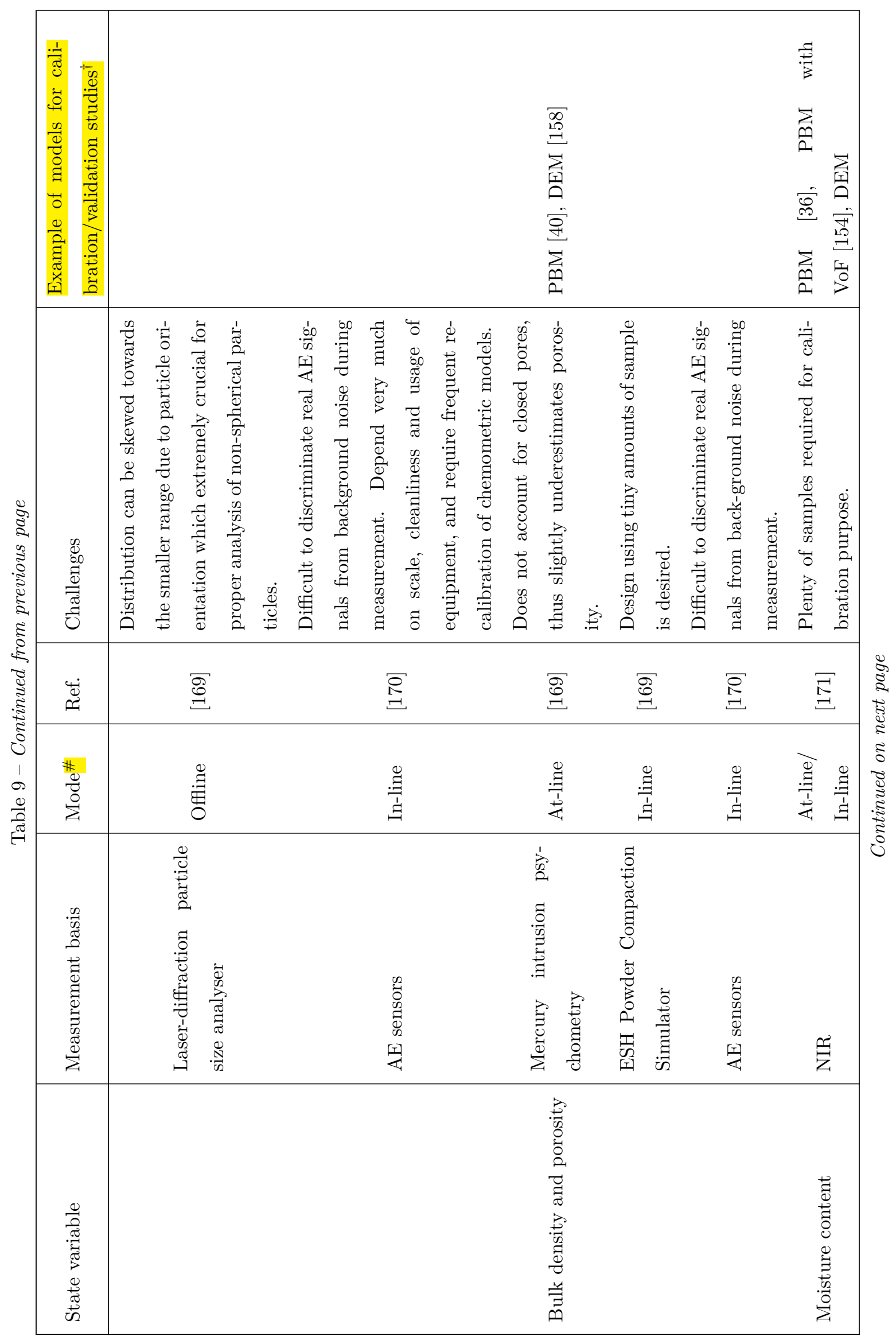






